\title{
Development of Ethics Education Guidelines for Undergraduate Athletic Training Education Programs
}

Kaitlynn Cullen

Follow this and additional works at: https://researchrepository.wvu.edu/etd

\section{Recommended Citation}

Cullen, Kaitlynn, "Development of Ethics Education Guidelines for Undergraduate Athletic Training Education Programs" (2017). Graduate Theses, Dissertations, and Problem Reports. 5417.

https://researchrepository.wvu.edu/etd/5417

This Thesis is protected by copyright and/or related rights. It has been brought to you by the The Research Repository @ WVU with permission from the rights-holder(s). You are free to use this Thesis in any way that is permitted by the copyright and related rights legislation that applies to your use. For other uses you must obtain permission from the rights-holder(s) directly, unless additional rights are indicated by a Creative Commons license in the record and/ or on the work itself. This Thesis has been accepted for inclusion in WVU Graduate Theses, Dissertations, and Problem Reports collection by an authorized administrator of The Research Repository @ WVU. For more information, please contact researchrepository@mail.wvu.edu. 
Development of Ethics Education Guidelines for Undergraduate Athletic Training Education Programs

Kaitlynn Cullen, LAT, ATC

Thesis submitted to the College of Physical Activity and Sports Sciences

At West Virginia University

In partial fulfillment-of the requirements

For the degree of

Master of Science

In

Athletic Training

Michelle A. Sandrey, PhD, ATC, Chair

Damien Clement, PhD, ATC, CC-AASP, NCC

Robert Bonser, DAT, ATC, PES

Department of Sport Sciences

Morgantown, West Virginia

2017

Keywords: Ethics Education, Athletic Training, Medical Ethics Copyright 2017 Kaitlynn Cullen 


\section{ABSTRACT}

Context: Since 2007, much of the literature has determined a need for recognition and resolution of ethical situations in the athletic training profession. Existing demographic studies suggest areas of improvement for athletic training education program (ATEP) ethics curriculum, however, little has been accomplished within the past nine years. The athletic training field has not addressed specific guidelines needed to teach ethics courses or an appropriate curriculum for the undergraduate ATEP setting. Educational guidelines should be developed for ethics education in undergraduate ATEPs. Objective: The purpose of this study is to develop guidelines for ethics education in undergraduate ATEPs. Design: This was a prospective-descriptive study that utilized an emailed questionnaire to describe and compare ethics educational guidelines using the Modified Delphi Technique. Setting: Questionnaires were distributed by email to select athletic training and ethics educators that have knowledge of medical ethics and athletic training education. Patients or Other Participants: Seven athletic training educators and three medical ethics educators were recruited for the panel. Inclusion criterion for this study specifically stated that the educator must have a minimum of 5 years experience as an athletic training program director, athletic training educator, medical ethics educator, or ethics committee member. The educators could also work at any level of university and teach in a multitude of health-related professional programs including: medicine, nursing, physical therapy, occupational therapy, and psychology. Exclusion criterion included educators that do not have the minimum 5-year experience with athletic training education or medical ethics-related curriculum and course work. Interventions: A 60 item questionnaire separated into seven total sections (demographic questions, curriculum components, athletic trainer misconduct, ethical competencies, educational methods, presentation of curriculum, and program requirements) was developed based on medical ethics literature for undergraduate medical, nursing, and allied health professions. A first round cover letter with a link to the questionnaire on Qualtrics was emailed to the participants. One follow up e-mail was sent to remind participants to complete the questionnaire. After two weeks, a second email with the questionnaire was sent with responses (frequencies, percentages, means and write-in comments) from the first round. Another follow-up e-mail was sent to remind participants to complete the final round questionnaire. Returned questionnaires were recorded on Qualtrics database for analysis. The guidelines for ethics training were developed based on the responses that met consensus (75\% agreement for strongly agree and agree and a mean score of 4) from the second round questionnaire. Main Outcome Measures: The dependent variables included curriculum components, athletic trainer misconduct, ethics competencies, educational methods, presentation of curriculum, and program requirements. Results: The final set of guidelines for ethics education consisted of 40 components from six sections. Statistical analysis of means and frequency ranges for each dependent variable found high consensus for Curriculum Components $(\mathrm{n}=17$, Mean R2=4.16, R2=20-80\%), Athletic Trainer Misconduct $(\mathrm{n}=5$, Mean $\mathrm{R} 2=4.36$, Freq $\mathrm{R} 2=$ $20-80 \%$ ), Ethics Competencies ( $\mathrm{n}=11$, Mean R2 $=4.56$, Freq R2 $=25-100 \%$ ), and Program

Requirements ( $n=5$, Mean R2=4.15, Freq R2=25-100\%). Overall, low consensus was found for the remaining two sections, Educational Methods (Mean R2 $=3.30$, Freq R2 $=25-75 \%$ ) and Presentation of Curriculum (Mean R2=2.80, Freq R2=25-75\%). Conclusion: Based on the information gathered through this prospective-descriptive study, the original ethics education guidelines contained 58 components with two write-in comments from the panel, for a total of 60 components. After the second round, 40 components met consensus. The responses by the panel of experts allowed for the development of guidelines for ethics education in undergraduate athletic training programs. 


\section{ACKNOWLEDGEMENTS}

"And I am convinced that nothing can ever separate us from God's love. Neither death nor life, neither angels nor demons, neither our fears for today nor our worries about tomorrow-not even the powers of hell can separate us from God's love. No power in the sky above or in the earth below - indeed, nothing in all creation will ever be able to separate us from the love of God that

is revealed in Christ Jesus our Lord." -Romans 8:38-39

To my husband

Garrett Cullen

Thank you for continuously loving me and supporting my (many) crazy dreams. Your words of encouragement always help me through the hardest days. I am so blessed to share this life with you.

To Dr. Sandrey

A special thank you to my committee chair, Dr. Michelle Sandrey. Thank you for your constant guidance throughout every draft and meeting. I wish the best of luck to you and future generations of the WVU graduate athletic training program.

To Dr. Clement

Thank you to committee member, Dr. Damien Clement. Thank you for volunteering your time and expertise to this research process. Your attention to detail helped significantly in the creation of this paper.

To Dr. Bonser

Thank you to committee member, Dr. Bobby Bonser. Thank you for being passionate about student growth, and for helping me navigate the emotional ups and downs of formal research.

"The secret in education lies in respecting the student." -Ralph Waldo Emerson

To my coworkers

Andy Palko, Erin Leaver, Jordan Ricks, and Kourtney Skinner

Thank you for two years of priceless memories, and for keeping me sane through the challenges of graduate school. Waynesburg University Athletic Training will forever hold a special place in my heart. 


\section{TABLE OF CONTENTS}

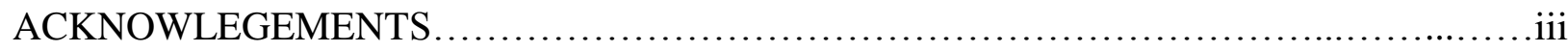

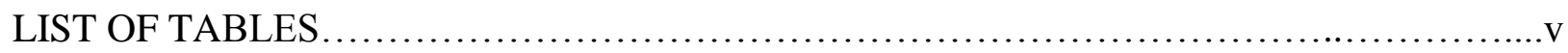

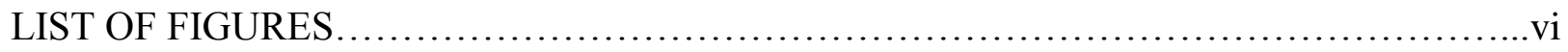

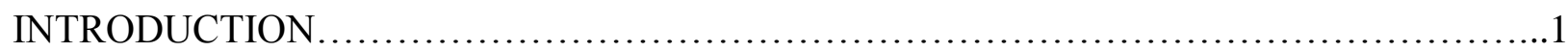

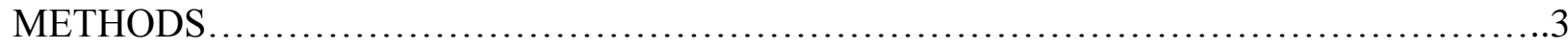

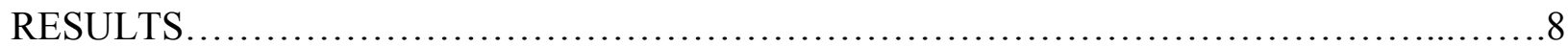

DISCUSSION ................................................................... 17

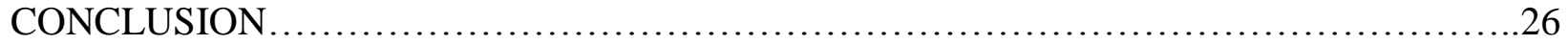

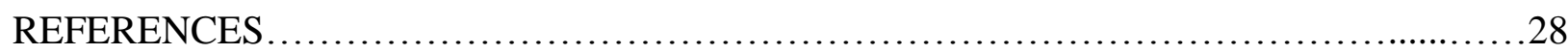

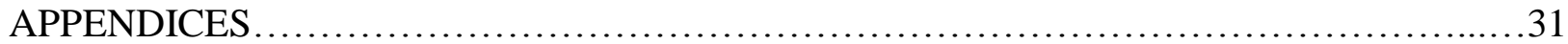

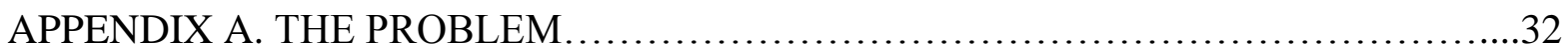

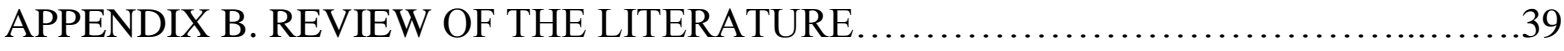

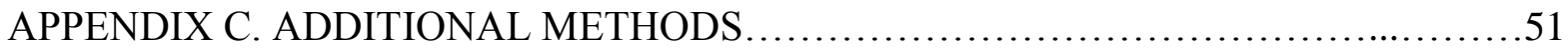

APPENDIX D. ADDITIONAL RESULTS .......................................68

APPENDIX E. RECOMMENDATIONS FOR FUTURE RESEARCH.................79

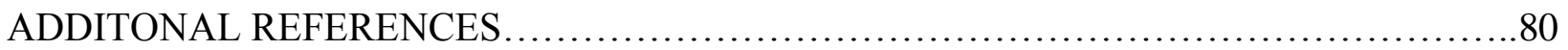




\section{LIST OF TABLES}

Table B1. Overall Goals of an Undergraduate Medical Ethics Program.......................42

Table B2. National Athletic Trainers' Association Code of Ethics...........................49

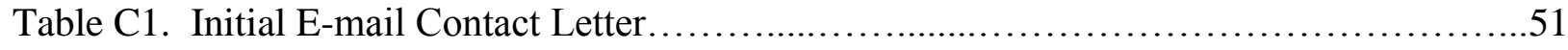

Table C2. Initial Cover Letter for Round One...........................................52

Table C3. Follow-up Cover Letter for Round One...................................53

Table C4. Cover Letter for Round Two..............................................54

Table C5. Follow-up Cover Letter for Round Two......................................55

Table C6. First Round Questionnaire............................................56

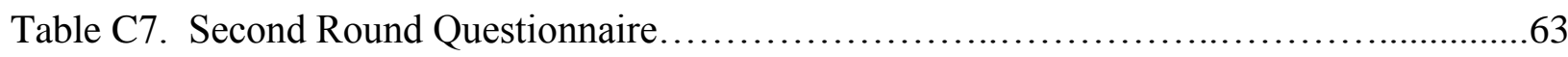

Tables D1.1-1.2. Participant Demographic Information...............................68

Table D2. Percentage Distribution and Mean Scores for First and Second Round Curriculum

Components.............................................................. 70

Table D3. Percentage Distribution and Mean Scores for First and Second Round Athletic Trainer Misconduct................................................................... 71

Table D4. Percentage Distribution and Mean Scores for First and Second Round Ethics Competencies.............................................................. 71

Table D5. Percentage Distribution and Mean Scores for First and Second Round Educational Methods

Table D6. Percentage Distribution and Mean Scores for First and Second Round Presentation of

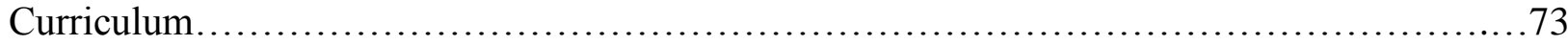

Table D7. Percentage Distribution and Mean Scores for First and Second Round Program

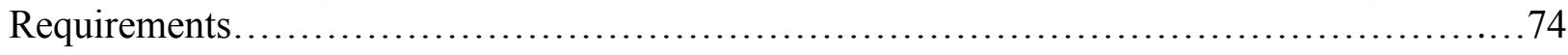

Table D8. Final Set of Ethics Education Guidelines......................................... 74 


\section{LIST OF FIGURES}

Figure D1. Example Phase Placement Timeline of Final Ethics Guidelines ....................77 


\section{INTRODUCTION}

Ethics, the study of morality, involves the continual examination of moral decisionmaking and human behavior. ${ }^{1,2}$ More specifically, morality measures the weight of a belief or decision based upon moral "goodness" or "badness." ${ }^{3}$ Filip et al. ${ }^{4}$ described morality as the foundation of a civilization, creating the standard for societal rules and laws. Within this ideology, every aspect of a society is affected by its members' accepted beliefs and behaviors. ${ }^{4}$

All healthcare and medical professional organizations have a code of ethics that members are to follow and is used for disciplinary action in cases of violation. Despite members being aware of the professional code of ethics, an even more critical factor is in the incorporation of ethics into education. Originating from the ideology of ancient Greek philosopher Aristotle, ethics education begins with the development of practical wisdom, or the ability to interpret and deliberate in ethical situations. ${ }^{5}$ Furthermore, Aristotle determined that maturity and experience are needed to establish practical wisdom. ${ }^{5}$ Noddings et al. ${ }^{6}$ elaborated further by developing the model of moral education through modeling, dialogue, practice, and confirmation. In short, students must be expected to practice moral decision-making and be guided through careful instruction by mentors. $^{7}$

Ethics education has evolved over time and varies with each professional program. Healthcare providers are frequently called to resolve difficult situations, sometimes not easily answered by scientific knowledge or methods. Bandman et al. ${ }^{8}$ recognized the high risk for moral concerns in the medical field. "Moral problems arise whenever and wherever there is a possibility of doing good or harm to someone."

Medical ethics, a branch of ethics study, deals with ethical concerns that arise within medical practice. ${ }^{2}$ Beginning in the early 1980 's, medical ethics education greatly evolved from 
a topic once deemed as unnecessary curriculum. ${ }^{9}$ At the forefront of ethics education, healthcare providers must develop moral sensitivity in their medical practice. ${ }^{10}$ Moral sensitivity is one's ability to recognize ethical problems and manage the situations in an ethical manner. ${ }^{10}$ This premise is highly valuable in ethical decision-making, for it serves as the driving force behind one's ambition to implement ethical practice. ${ }^{10}$ Gold et al. ${ }^{11}$ seconded this ideology by affirming that students must learn to provide best practice through "moral knowing and feeling". This allows students to develop empathy for the individuals that they care for. Today, professional education programs for medical, nursing, and allied health disciplines have taken notice to the need for medical ethics education.

In conjunction with other healthcare professions, the athletic training (AT) profession also lacks a strong foundation of moral and ethical education for its members. The National Athletic Trainers' Association (NATA) Code of Ethics provides practicing athletic trainers with an outline of the association's expectations and recommendations for appropriate behavior within the athletic training profession. ${ }^{12}$ Even with outlined expectations, athletic trainers continue to encounter difficult situations, or "grey areas," that are not easily identified or resolved using the non-specific language of the NATA Code of Ethics.

Since 2007, much of the literature has determined a need for recognition and resolution of ethical situations in the AT profession. ${ }^{7}{ }^{13-15}$ Existing demographic studies suggest areas of improvement for athletic training education program (ATEP) ethics curriculum, however, little has been accomplished within the past nine years. ${ }^{7,16}$

William's 2007 survey determined that only 12 out of 106 AT educators reported offering a stand-alone ethics course to meet the Commission on Accreditation of Athletic Training Education (CAATE) requirements. ${ }^{7}$ Participants of the same survey also stated that 
ethics teaching is harshly limited in the classroom and clinical settings. Of participants surveyed, 39 percent reported zero hours of ethics teaching each semester, while 83 percent reported a maximum of only nine hours per semester. ${ }^{7}$

Throughout investigation of the literature, it is clear that the athletic training field has not addressed specific guidelines needed to teach ethics courses or an appropriate curriculum for the undergraduate ATEP setting. Athletic trainers play a significant role in the US healthcare system by not only practicing in athletic settings, but physician practice, physical therapy clinics, hospital settings, cardiac rehabilitation centers, occupational health departments, military and police academies, and performing arts. ${ }^{17}$ With a growing field of more than 48,000 certified athletic trainers, it is imperative that undergraduate ATEPs prepare students to enter the workforce as ethically sound professionals. Therefore, the purpose of this study is to develop guidelines for ethics education in undergraduate athletic training programs.

\section{METHODS}

Design

A prospective study design was utilized to develop educational guidelines for undergraduate athletic training programs. The guidelines were determined by administering a questionnaire to athletic training and ethics educators. For data collection and synthesis, this study utilized the Modified Delphi Technique.

\section{Participants}

A minimum of 12 participants were needed to compile a panel of athletic training and ethics experts. The subject population was fulfilled by educators that have experience with athletic training education or medical ethics-related curriculum and course work. Past experience allowed these educators to understand the necessary objectives for training students to maintain 
professionalism and ethical integrity in the workplace. These participants also understood the value of ethical practice and its effect on patient care. Thus, the subjects included in this study were athletic training or ethics educators at the higher education level.

Inclusion criterion specifically stated that the educator must have a minimum of 5 years experience as an athletic training program director, athletic training educator, ethics educator, or ethics committee member. These educators worked in Division I-III institutions and taught in a multitude of health-related professional programs including: medicine, nursing, physical therapy, occupational therapy, and psychology. Exclusion criterion included educators that did not have experience with athletic training education or medical ethics-related curriculum and course work. The West Virginia University Office of Research Compliance approved this study. Instruments

Medical ethics curriculum outlined in studies, readings, and websites were utilized to create the Ethics Education Guidelines in Athletic Training Questionnaire, otherwise known as EEGAT questionnaire. The areas outlined were demographic information, curriculum components, athletic trainer misconduct, ethics competencies, educational methods, presentation of curriculum, and program requirements. A Likert scale rated outcomes with 1 strongly disagree, 2 disagree, 3 neutral, 4 agree, and 5 strongly agree.

This questionnaire included fifty-eight questions separated into seven total sections. The first section collected participant demographics, which included education, work setting, publications and presentations, and curriculum presentation questions. The second section of the questionnaire included curriculum components to develop specific objectives within an ethic course $(n=19)$. The third section of the questionnaire included common types of athletic trainer misconduct that students should be educated against $(n=5)$. The fourth section included ethics 
competencies to allow students to practice application of ethics concepts $(n=12)$. The fifth section included educational methods to deliver the course information to students $(n=12)$. The sixth section of the questionnaire included presentation of curriculum, which determined the necessary course length and frequency to fully cover all objectives in the curriculum $(n=5)$. Program requirements were included in the final section of the questionnaire $(n=5)$. This outlined specific requirements set by the athletic training program to determine student completion.

Face and content validity of this questionnaire were obtained with feedback from an athletic training program director experienced in educational methods $(n=1)$, athletic training educators $(n=2)$, a psychometric expert $(n=1)$, and an outside party not well versed in the subject $(n=1)$. These individuals read the questionnaire to evaluate clarity, content, design, and face validity.

The Modified Delphi Technique

Due to insufficient information about ethics education in athletic training, the Modified Delphi Technique (MDT) was implemented as the primary data collection tool of this study. Unlike the traditional scientific method, the MDT does not attempt to create new knowledge, but investigates the current wisdom and expertise of a panel of participants. ${ }^{18,19}$ As described by Ziglio, ${ }^{20}$ the MDT is "a structured process for collecting and distilling knowledge from a group of experts by means of a series of questionnaires interspersed with controlled opinion feedback." Most importantly for this study, the MDT has been utilized for nearly 50 years and is praiseworthy for its use of developing educational curriculum. ${ }^{21}$

The MDT consists of two rounds of questionnaires delivered to a selected panel of experts. Unlike other data collection methods, the panel of experts does not assist in formulating the questionnaire, but attempts to answer each question from background knowledge and 
expertise. ${ }^{19,21,22}$ In the first round, questions are less structured, and feedback from the participants is welcomed by allowing each respondent to write-in additional comments. ${ }^{19,21}$ The responses from the first round are analyzed, and mean scores, frequencies, and percentages are produced. In the second round, the participants complete the same questionnaire with access to the original results of the first questionnaire. ${ }^{19}$ These responses are then analyzed to determine the consensus among participants and used to create the educational guidelines.

The MDT provides multiple advantages during the research process. First and foremost, the greatest advantage is the ability to motivate the involved participants. ${ }^{19}$ The participants collectively adopt the problem in question and work together to claim a uniform decision. ${ }^{22}$ Compared to traditional group meetings, the MDT also eliminates influential personalities and allows each participate to answer with anonymity. ${ }^{18-22}$ Lastly, the MDT provides inexpensive data collection through electronic questionnaires that are easily distributed to participants in a time-efficient manner. ${ }^{23}$

Outside of advantages, there are also a number of limitations when using the MDT. The most prominent limitation of this technique is the extended amount of time between each round of cover letters and questionnaires. Many participants drop out of the study due to long wait times between questionnaires and distributed materials. Retention rates may be improved by setting distinct return and follow up dates for investigators ${ }^{19,22}$ Although the investigator attempts to recruit subjects perceived as "experts" in their field, some participants may not be qualified to provide applicable advice. Due to this fact, some feedback may be skewed in the data collection process. ${ }^{19,2122}$ Recruiting enough participants to provide meaningful results is another limitation of the MDT. This may be counteracted by recruiting a large number of participants in hopes of securing a minimum of 12 participants. $^{19,21,22}$ 
Procedures

Athletic training educators or ethics educators across all university divisions were selected. Athletic training program directors and program leaders were contacted to obtain names and e-mail addresses for athletic training and ethics educators.

An initial e-mail contact letter (Table C1) was sent to gauge interest in study participation to educators in the university setting. Individuals that were interested in participating in the study were sent the initial cover letter (Table C2) containing the hyperlink for the first round questionnaire (Table C6) as well as a demographic questionnaire to complete. A follow up letter (Table C3) was sent within two weeks to remind the participants to return the first round questionnaire. Once the first round questionnaires were returned, frequencies and percentages of the responses were accumulated. The second round questionnaire (Table C7) contained these frequencies and percentages with write-in comments that participants included in the first round. The second round questionnaire was sent two weeks after the deadline for the first round, to those that completed the first round questionnaire. Another cover letter (Table C4) was sent via e-mail, and a follow up letter (Table C5) was e-mailed within two weeks to remind the participants to return the second round questionnaire.

Statistical Analysis

The statistical analysis included frequencies and percentages from the two rounds of questionnaires sent to participants. The participants rated responses on a five-part Likert scale ( $1=$ strongly disagree, 2 =disagree, $3=$ no opinion, $4=$ agree, $5=$ strongly agree). Responses to each of the 58 questions and comments were tabulated. A consensus of $75 \%$ or higher was utilized; having the responses agree and strongly agree and a mean score of 4 on the Likert scale for each component. The consensus responses and comments from the first round questionnaire were 
used to generate the second round questionnaire. The final results of the second round questionnaire were utilized to generate the ethics educational guidelines for undergraduate athletic training programs.

\section{RESULTS}

A link to the demographic questionnaire was emailed to the respondents, along with the Round One Questionnaire through Qualtrics. Of the 50 initial emails that were sent to possible participants, 11 participants responded and were sent the follow-up information, including the demographic questionnaire, along with Round One. For the first round of the survey, there was a 22 percent response rate. Seven of the participants were certified ATCs $(n=7,63.64 \%)$ who met the inclusion criteria and three were medical ethics educators $(n=3,36.36 \%)$. One participant was excluded due to not having at least five years of experience in athletic training education or medical ethics education.

Certified Athletic Trainer Survey Demographics

The ATCs employment areas were reported as follows: athletic training program director $(n=2,28.57 \%)$, clinical coordinator $(n=2,28.57 \%)$, and educator $(n=4,57.14 \%)$, along with one participant who served as athletic training faculty and associate dean. One athletic training educator reported dual experience as a medical ethics member of a professional-level organization. Number of ethics-related presentations at local conferences were zero presentations $(\mathrm{n}=6,85.71 \%)$ and $1-3$ presentations $(\mathrm{n}=1,14.29 \%)$. For regional conferences, zero presentations $(n=4,57.14 \%)$ and $1-3$ presentations $(n=3,42.86 \%)$. At national-level conferences, zero presentations $(n=4,57.14 \%)$ and $1-3$ presentations $(n=3,42.86 \%)$. Number of peer-reviewed publications in the area of ethics education were zero presentations $(n=6,85.71 \%)$ and $1-3$ presentations $(n=1,14.29 \%)$. Number of hours of student ethics training per semester in current 
institution were zero $(n=2,20.00 \%), 1-3$ hours $(n=2,20.00 \%), 4-6$ hours $(n=2,20.00 \%), 7-9$ hours $(n=0,0 \%), 10-12$ hours $(n=0,0 \%), 12+$ hours $(n=0,0 \%)$. Overall, the majority of ATCs had achieved doctorate-level degrees as $\operatorname{PhD}(n=4,57.14 \%), \operatorname{EdD}(n=1,14.29 \%)$, or DHSc $(n=1$, $14.29 \%)$, while only one reported obtaining a Master of Science $(n=1,14.29 \%)$. ATCs reported working at the Division I ( $\mathrm{n}=4,57.14 \%)$, Division II $(\mathrm{n}=1,14.29 \%)$, and Division III $(\mathrm{n}=2$, $28.57 \%$ ) institutions. Refer to Table D1.1 for demographic information. Medical Ethics Educator Survey Demographics

All three medical ethics educators reported having $\operatorname{PhD}(n=3,100 \%)$ degrees and current employment at Division I ( $\mathrm{n}=3,100 \%)$ institutions. Number of ethics-related presentations at local conferences were zero presentations $(n=1,33.33 \%)$ and 10 or more presentations $(n=2$, $66.67 \%)$. For regional conferences there were zero presentations $(n=1,33.33 \%)$ and 10 or more presentations $(\mathrm{n}=2,66.67 \%)$, while for national-level conferences there were zero presentations $(n=1,33.33 \%)$ and 10 or more presentations $(n=2,66.67 \%)$. Number of peer-reviewed publications in the area of ethics education were zero publications $(n=1,33.33 \%)$ and 10 or more publications $(n=2,66.67 \%)$. Number of hours of student ethics training per semester in current institution were zero $(n=0,0 \%), 1-3$ hours $(n=0,0 \%), 4-6$ hours $(n=0,0 \%), 7-9$ hours $(n=0,0 \%)$, 10-12 hours $(n=0,0 \%), 12+$ hours $(n=2,20.00 \%)$. One ethics educator identified as an athletic training educator, however, this participant was not a certified athletic trainer. Refer to Table D1.2 for demographic information.

Ethics Education Guidelines for Undergraduate Athletic Training Programs Questionnaire In order for each of the question components to influence the final set of guidelines, a $75 \%$ consensus of strongly agree and agree with a mean score of 4 was required for the second round. All of the educational components from the first round remained in the second round 
questionnaire for the participants' review of scores. Additional write-in questions were also added in each round.

Curriculum components: In the first round of this section, all 19 curriculum components were rated highly. The mean score and frequency range were 4.83 and 11.1 to 100.00 percent, respectively. Three write-in comments were included in this section; however, no pertinent information could be drawn to formulate new questions. The first two comments primarily focused on the clarity and formatting of the questions, and the third comment explained that the participant had experience only in medical ethics education. After the second round, seventeen out of nineteen curriculum components had a $75 \%$ consensus and mean score of 4.16 . The frequencies ranged from 20.00 to 80.00 percent in the second round. There were no write-in comments for the second round.

The curriculum components that remained were: Students should know and understand the NATA Code of Ethics, professional behaviors standards of their practicing state, ATEP code of ethics, professional responsibilities of an AT, as well as ethical obligations of the AT profession. Ethical concepts of patient autonomy, beneficence, nonmaleficence, and patient informed consent were also included. Finally, clarification between personal, professional, and organizational values, personal and professional moral beliefs of themselves and other people, barriers to ethical practice, situations of unethical decision-making, reporting ethical concerns, communication with other healthcare providers to resolved ethical situations, and legal consequences or unethical decision-making also remained. See Table D2 for curriculum components results.

Athletic trainer misconduct: In round one, all 5 misconduct components were rated highly. This section assessed different types of athletic trainer misconduct that should be 
included within AT ethics education. The mean score and frequency range were 4.87 and 10.00 to 100.00 percent, respectively. Two write-in comments were included in this section; however, no pertinent information could be drawn to formulate new questions. The first comment primarily focused on the clarity and formatting of the questions, and the second comment explained that the participant did not understand common types of athletic trainer misconduct well enough to give an informed response.

In the second round, five out of five areas of misconduct met consensus of $75 \%$ and mean score of 4.36. The frequencies ranged from 20.00 to 80.00 percent in the second round. There were no write-in comments in this section. The components that met criteria were: Students should know and understand the common types of unethical athletic trainer misconduct including sexual conduct, boundary conflicts, economic self-interest, substance abuse, and disruptive AT behavior. See Table D3 for athletic trainer misconduct results.

Ethics competencies: In round one, 12 out of 12 ethics competencies were rated highly. This section assessed what ethics competencies students should be required to practice as a part of clinical education requirements. The mean score and frequency range were 4.56 and 10.00 and 90.00 percent, respectively. Three write-in comments were included in this section, which provided important information for formulating three new questions for the second round questionnaire. Participant 1 commented that students should not be allowed to act as the primary decision-maker in ethical situations. The participant felt that the supervising preceptor should act as the primary decision-maker, ideally with input from the student.

Participant 2 expressed concern for students demonstrating the ability to handle a patient who is incompetent to make medical decisions and withholding medical information. The participant commented that only physicians have the right to determine competence and withhold 
medical information (therapeutic privilege). Lastly, the participant did not agree with students demonstrating a consultation with an institutional ethics committee, as "ethics consultations require extensive education and skill building--while being aware of the process is important." Participant 3 commented only on clarity and formatting of the questions.

In the second round, 11 of 15 ethics competencies met consensus of $75 \%$ and mean score of 4.56. The frequencies ranged from 25.00 to 100.00 percent in the second round. There were no write-in comments for the second round. The competencies that met consensus included: Students should demonstrate ethical standards that correspond with NATA Code of Ethics, document a patient's informed consent, act appropriately if patient is incompetent to make medical decisions or refuses treatment, as well as document patient's refusal of treatment.

Deciding when it is ethically justified to breach patient confidentiality, manage conflicting ethical opinions with a patient, and deliver information in situation of poor prognosis were also included. Incorporating a team approach when handling ethical issues also remained. The panelist agreed that students should not act as the primary decision-maker when dealing with ethical situations in the AT setting, but that they should play an active role in helping the preceptor decide on a plan of action. See Table D4 for ethics competencies results.

Educational methods: In the first round, 2 of 12 educational methods were rated highly. This component assessed specific methods that educators should utilize when teaching ethicsrelated curriculum. The mean score was 3.46 and frequency range of 10.00 to 80.00 percent, respectively. Two write-in comments were included in this section; however, no pertinent information could be drawn to formulate new questions. Both comments primarily focused on the formatting of the questions, and requested clearing phrasing to prevent reader confusion. 
In the second round, 1 of 12 educational methods met consensus. The mean range was 3.30 and frequency range of 25.00 to 75.00 percent. There were no write-in comments for the second round. The component that met consensus included: Ethical decision-making is effectively taught through case study discussion in the classroom. See Table D5 for educational methods results.

Presentation of curriculum: In the first round, 0 of 5 components were rated highly. This section assessed different methods of delivering ethics training. The mean score and frequency range were 2.96 and 10.00 to 60.00 percent, respectively. There were no comments at the end of this section. In the second round, 1 of 5 components met consensus. There was a mean score of 2.80 and frequency range of 25.00 to 75.00 percent. There were no write-in comments for the second round. The component that met criteria included: Ethics training is best delivered through a stand-alone course. See Table D6 for presentation of curriculum results.

Program requirements: In the first round, all five program requirements were rated highly. This section assessed specific requirements that athletic training programs should uphold for student advancement. The mean score and frequency were 4.24 and 10.00 to 60.00 percent, respectively. One write-in comment was included in this section. The participant stated, "I think it is a good point to remind preceptors about their ethical responsibility not only to their patients but to the students. It may help the preceptor identify with the student's ability to utilize their ethical decision making skills." Due to the fact that a similar question pertaining to preceptor ethics training was already included in round one, no new questions were added for the second round.

In the second round, all five educational methods met consensus. The mean was 4.15 and frequency range of 25.00 to 100.00 percent. There were no write-in comments for the second 
round. The components that met consensus included: Undergraduate AT program should require students to complete ethics training before entering clinical rotations, complete clinical competencies on ethics content, students complete yearly ethics training, educators who teach ethics-related content should have a background experience in ethics education, and athletic training preceptors should be required to complete ethics training. See Table D7 for program requirements results.

Variance Between Rounds

There were components that were rated highly in the first round that did not meet consensus in the second round. Overall, 15 components were below consensus after the first round and 20 non-consensus components after the second round. In Curriculum Components, the panel did not agree that relevant medical ethics history or ethical decision-making frameworks should be included within the program curriculum. For Ethics Competencies, the panel did not agree that students should practice deciding when it is ethically justifiable to withhold patient information. The panel also rejected the idea of students demonstrating the ability to evaluate an employment contract for unethical language or conducting a consultation with an institutional ethics committee.

The majority of non-consensus components were found in the Educational Methods section. The panel disagreed against utilizing the follow methods for teaching ethical decisionmaking: role-play, scenario-based exercises, reflective journaling, mentoring, behavior modeling, clinical experience, educational games, small group activities, classroom presentations, writing assignments, or research papers. Several non-consensus components were also found in the Presentation of Curriculum section. The panel did not agree that ethics training 
should be delivered to students within a larger course, online module, professional conference, or journal publications.

The results were affected by the participants changing responses, as well as a decrease in the number of participants between rounds. There were ten participants in the first round and five participants in the second round. Based on the Modified Delphi Technique, an increase in means and percentages would be evident for the second round because the participants were shown the results from the first round when they received the second round questionnaire. Consensus was created because participants could change their responses between rounds. Final Set of Guidelines

Components that met consensus in the second round formed the educational guidelines for ethics education in accredited undergraduate athletic training programs. Of the 58 original items on the first round of the questionnaire, 38 met consensus in the second round and two write in questions for a total of 40 questions. Two components were added based on additional comments from participants. These two questions were added in the Ethics Competencies section.

Overall, the ethics education guidelines that were developed contained information from current literature and expertise from both athletic training and medical ethics educators. In the Curriculum Components section, most of the objectives that involved general medical ethics concepts and athletic training profession standards met consensus, except for teaching students the most relevant medical ethics history and utilizing ethical decision-making frameworks when formulating a plan of action. One participant provided an additional comment that discussed the danger of utilizing ethical decision-making frameworks as mere "check-lists", instead of individually considering and tending to specific details of the situation. 
The Athletic Trainer Misconduct section was based on reported cases in athletic training literature. There was a brief discussion in the literature about addressing specific forms of athletic trainer misconduct and informing students on the consequence associated with such behaviors. The panelists did agree that students should be educated on common forms of athletic trainer misconduct including sexual conduct, boundary conflicts, economic self-interest, substance abuse, and disruptive AT behavior.

The Ethics Competencies section was formulated from literature in the medical, nursing, and physical therapy professions. Much of the literature provided specific course syllabi for individual education programs, mainly from medical schools. The panel agreed that students should practice handling and documenting situations in which the patient is incompetent to make medical decisions or refuses medical treatment. The panel also came to the consensus that students should be able to justify when it is necessary to breach patient confidentiality and how to deliver a poor prognosis. These consensus objectives are crucial parts of patient care that many athletic trainers may experience throughout their careers.

The Educational Methods section was formulated from literature in the nursing profession. Much of the literature provided specific course standards for individual education programs and nursing ethics panels within medical institutions. The panel agreed only upon one objective that ethical decision-making is most effectively taught through case study discussion in the classroom. While oftentimes used for educational development, role-play, scenario-based exercises, reflective journaling, mentoring, behavior modeling, clinical experience, educational games, small-group activities, classroom presentations, writing assignments, and research papers were not agreed upon. The panel felt that these were not the best methods to employ. 
The Presentation of Curriculum section was formulated from demographic studies in athletic training literature. Although scarce, the literature discussed that many undergraduate athletic training programs do not have a set standard for presenting ethics-related curriculum. The panel agreed only upon one objective that ethics training is best delivered through a standalone course. Dramatically lower scores were found in presenting ethics-related curriculum within larger courses, online modules, professional conferences, and journal publications.

The final section, Program Requirements, was formulated from demographic studies in athletic training literature. No set standard of program requirements has been established to universalize ethics training in undergraduate athletic training programs. The panelists agreed that undergraduate ATEPs should require students to complete both pre-admission and yearly ethics training, along with clinical competencies on ethics content throughout the course of the program. The panel also agreed that educators who teach ethics-related content should have a background experience in ethics education and athletic training preceptors should be required to complete ethics training. See Table D8 for final set of educational guidelines.

\section{DISCUSSION}

The purpose of this study is to develop guidelines for ethics education in undergraduate athletic training programs, using a select panel of athletic training educators and medical ethics educators to generate consensus on ethics education components. The intent was to design a set of guidelines that athletic training educators can utilize when incorporating ethics curriculum into undergraduate athletic training programs. Since 2007, much of the literature has determined a need for recognition and resolution of ethical situations in the AT profession. ${ }^{7,13-15}$ Existing demographic studies suggested areas of improvement for athletic training education program (ATEP) ethics curriculum, however, little has been accomplished within the past nine years. ${ }^{7,16}$ 
This protocol cannot be generalized to all undergraduate athletic training programs, due to the resources and personnel available at those institutions.

The goal of this study was to determine what components should be included within ethics education guidelines for undergraduate athletic training students. The participants included athletic training educators and medical ethics educators who were selected to complete two rounds of questionnaires to develop the educational guidelines. This panel consisted of experts in the area of athletic training education and medical ethics education. They all shared valuable knowledge that led to the development of educational guidelines for athletic training ethics education. This panel was consistent with the original hypothesized group of experts. However, the participant sample size did not reach the minimum requirement of 12 respondents for both rounds.

A review of the literature was performed first to gather the information that would be included in the proposed educational guidelines for ethics education. Current literature from medical, nursing, physical therapy, and athletic training programs was compiled into a questionnaire before submitting to a select panel of experts following the Modified Delphi Technique. The Modified Delphi Technique allowed the panel of experts to record their opinions for two rounds on ethics education components that were divided into six sections: Curriculum Components, Athletic Trainer Misconduct, Ethics Competencies, Educational Methods, Presentation of Curriculum, and Program Requirements. The components that reached consensus ( $75 \%$ consensus and a mean score of 4$)$ following the second round were used to create the final set of guidelines (Table D8, Figure D1).

It was assumed that responses from the participants for each component would meet consensus of $75 \%$ and a mean score of 4 . Although all 60 questions did not meet consensus, 40 
ethics education components from the literature reached consensus and were used to design a set of guidelines of ethics education in undergraduate athletic training programs. There were sections (Curriculum Components, Athletic Trainer Misconduct, Ethics Competencies, Educational Methods, Program Requirements) that a majority of components met consensus after two rounds. The components that reached consensus were then compared to the literature.

Overall, a strong set of guidelines for ethics education for undergraduate athletic training programs was developed (Table D8). This set of guidelines contained multiple sources from current literature in the medical, nursing, physical therapy, and athletic training fields. Twenty components were eliminated after two rounds of the questionnaire; however, the components that remained created a descriptive set of guidelines for incorporating ethics curriculum within undergraduate athletic training programs. The guidelines are practical and useful for both AT programs looking to create a stand-alone ethics course and for athletic training educators looking to incorporate content into current ethics curriculum. These guidelines may be used by athletic training educators in all institutions, as all athletic training students should learn to handle ethical situations in a professional manner.

The Participant Population

The development of ethics education guidelines is based on the responses and opinions of ten participants who were considered experts in the field of medical ethics. These panelists were selected based upon the criteria of five years of experience within athletic training education (program director, clinical coordinator, and educator) or medical ethics educator. Participants were recruited from all divisions, but primarily from the Division I level.

Ten participants were included in the first round of responses, and though all were eligible, five responded in the second round. Although ten participants is a small sample, the 
credentials, years of experience, and experience with publications and presentations, make the participants in the study clear experts in the field of ethics education. The majority of participants hold a doctorate-level degree ( $\mathrm{PhD}, \mathrm{EdD}, \mathrm{DHSc})$, with only one participant reporting a master's degree in athletic training. This panel of experts was also highly qualified in ethics education, as the publication range was from 1-10 publications in peer-reviewed journals. In addition to publications, presentations at local, regional, and national conferences were also evident in a majority of the participants.

The modified Delphi Technique only requires a small sample size for adequate results. Current literature suggested at least twelve members in the panel; however, there is not a minimum requirement for number of participant, ${ }^{19,21,22}$ with the number varying dependent on the resources available and the scope of the problem. A limitation of the modified Delphi Technique was that the researcher could not control the expertise of the panelists. Fortunately in this study, the panelists have many years of experience as athletic training and medical ethics educators with presentations and publications. Although there were only ten participants in the first round and five in the second round, the extent of the experience of the participants created a practical set of guidelines for ethics education in undergraduate athletic training programs. The Final Protocol

The final set of guidelines for ethics education consisted of 40 components from six sections. The objective was to design a set of guidelines that athletic training educators can utilize when incorporating ethics curriculum into undergraduate athletic training programs. Since 2007, much of the literature has determined a need for recognition and resolution of ethical situations in the AT profession. ${ }^{7,13-15}$ Existing demographic studies suggested areas of 
improvement for athletic training education program (ATEP) ethics curriculum, however, little has been accomplished within the past nine years. ${ }^{7}, 16$

William's 2007 survey determined that only 12 out of 106 AT educators reported offering a stand-alone ethics course to meet the Commission on Accreditation of Athletic Training Education (CAATE) requirements. ${ }^{7}$ Participants of the same survey also stated that ethics teaching is harshly limited in the classroom and clinical settings. Of participants surveyed, 39 percent reported zero hours of ethics teaching each semester, while 83 percent reported a maximum of only nine hours per semester. ${ }^{7}$ Due to lack of ethics education within the athletic training field, undergraduate programs should be provided with a set of guidelines to help create ethics courses or improve current ethics-related curriculum. Each of the six sections included components to help athletic training educators to produce ethically sound, young professionals.

In the Presentation of Curriculum section, the panel was adamant that ethics education should be presented through a stand-alone college course. As reported in current literature, very few undergraduate athletic training programs offer stand-alone ethics courses, often harshly limited in the clinical and classroom settings. ${ }^{7}$ Ethics curriculum requires consistent amounts of training time to deliver all necessary subject material. ${ }^{29}$ From the expert panel's consensus, it is recommended that undergraduate athletic training programs work to implement stand-alone courses for ethics curriculum.

The final set of ethics education guidelines was organized into an example time-line placement model to simplify the process of incorporating ethics curriculum into undergraduate ATEPs (Figure D1). Establishing a base of ethical concepts would consist of patient autonomy, beneficence, nonmaleficence, patient informed consent, and barriers to ethical practice are introductory concepts that may be discussed in beginning phases 1 and 2. Each of these concepts 
influences decision-making skills by driving medical professionals to place patient desires and well-being at the forefront of medical decisions and actions. ${ }^{24}$

Alongside these concepts, students should begin to practice identifying personal, professional, and organizational values, as well as personal and professional moral beliefs of themselves and other people. Congruent with the literature, it is important for healthcare providers to develop moral sensitivity in their medical practice, as well as determine the personal and professional moral commitments of themselves and other people. ${ }^{10,11,25,26}$ By the end of introductory phases 1 and 2, students should begin applying their knowledge of ethical concepts by practicing proper documentation of patient informed consent and refusal of treatment.

Transitioning into phases 3 and 4 of instruction, educators should discuss NATA Code of Ethics, professional behavior standards of their practicing state, ATEP code of ethics, professional responsibilities of an AT, as well as ethical obligations of the AT profession. As written, the National Athletic Trainers' Association (NATA) Code of Ethics provides practicing athletic trainers with an outline of the association's expectations and recommendations for appropriate behavior within the athletic training profession. ${ }^{12}$ A strong understanding of professional behavior and ethical decision-making is very important for preparing undergraduate athletic training students to uphold high ethical standards of practice.

After providing background information and skills, phases 5 and 6 allow students to learn about common types of unethical athletic trainer misconduct including: sexual contact with patients, boundary conflicts, economic self-interest, substance abuse, and disruptive AT behavior. Not only should students be competent in handling the patient's needs, they must also understand the importance of acting in a manner that does not breach the professional patientclinician relationship. 
Romantic relationships or sexual contact with a patient is strictly prohibited and may cause the clinician to make decisions based on emotional ideation, rather than evidence-based, logical thinking. Boundary conflicts arise when the athletic trainer uses a position of power to influence the patient's medical decisions, compromising the patient's right to appropriate care. ${ }^{12}$ The patient's rights may also be violated when the athletic trainer allows economic self-interest to dictate a decision-making process, meaning that receiving financial compensation encourages poor clinician decision-making on the patient's behalf. ${ }^{12}$ Athletic training students should also be aware that substance abuse in the workplace may result in slowed reaction time and detrimental consequences to a patient's health. ${ }^{12}$

Along with identifying types of athletic trainer misconduct, educators must also discuss legal consequences of unethical behavior. Congruent with current literature, ethics education should be presented through case study discussion. Nursing literature discussed the importance of lecture and discuss-style teaching methods for ethics course curriculum. ${ }^{28}$ Conducting a factual evaluation of an ethics situation allows students to discuss specific legal consequences and identify relevant ethical principles. ${ }^{26}$ From the expert panel's consensus, it is recommended that undergraduate athletic training programs work to utilize case study discussion when educating students on ethical decision-making.

Lastly, ethics competencies are practiced in phases 7 and 8 . Although programs may provide curriculum covering code of ethics material, additional training should be provided to help students develop ethical decision-making skills. ${ }^{27} \mathrm{~A}$ competency-based approach enhances students' abilities by strengthening moral and professional integrity, avoiding moral distress, justifying difficult ethical decisions, and collaborating with other health professionals. ${ }^{26}$ Students should practice ethical standards that correspond with the NATA Code of Ethics by reporting 
ethical concerns and communicating with other healthcare providers to resolve ethical situations. Open dialogue about ethical-situations also allows students to understand the importance of effective communication in the workplace. ${ }^{6}$

Development of deliberative competencies assists students in generating a plan of action through group collaboration and consensus building. ${ }^{26}$ Creating a plan of action is vital in helping the student to determine when it is ethically justifiable to breach patient confidentiality, managing conflicting ethical opinions with the patient, and delivering information in the event of a poor prognosis. Above all else, students must grasp practical wisdom in order to interpret and deliberate in ethical situations. ${ }^{5,25}$ Ethics competencies must be practiced in a real-world setting, versus teaching students to utilize abstract principles in ethical situations.

Additionally, the expert panel agreed that undergraduate athletic training programs should require students to complete ethics training before entering clinical rotations, as well as yearly ethics training refreshers. Instruction for medical students in medical ethics and human values, both prior to and during participation in patient care activities, allows one to behave ethically in caring for patients and in relating to patients' families and others involved in patient care. ${ }^{30}$ The panel also agreed that educators who teach ethics-related content should have background experience in ethics education. According to the Liaison Committee of Medical Education, the faculty of a medical school ensure that the medical curriculum includes instruction for medical students in medical ethics and human values. ${ }^{30}$ Moving forward, undergraduate athletic training programs should strive for appropriate staffing of professors specifically trained in ethics education.

Also consistent with the literature, the panel agreed that athletic training preceptors should also be required to complete ethics training. Modeling educates others about ethical care 
through an outward expression of acceptable behaviors, or in other words, "leading by example." Health care educators who express high professional and moral standards impress upon students to follow suit. ${ }^{6}$ For long-term understanding of ethical practice, students must be expected to practice moral decision-making and be guided through careful instruction by mentors. ${ }^{7}$ It is strongly recommended that undergraduate athletic training programs implement preceptor training to ensure that students are learning from ethically competent leaders. Clinical Implications

Results from this study suggest that athletic training education programs are attempting to incorporate some ethics-related material into curriculums; however, this is inconsistent across all programs. Although only a small number of participants answered the question, fewer than 6 hours per semester are utilized in current athletic training education programs. These findings are congruent with Williams et al. ${ }^{7}$, who determined nine years ago that athletic training education programs were scarcely providing ethics education at all. While similar to Williams et al. ${ }^{7}$, this study differs by attempting to provide applicable guidelines for ethics education in undergraduate athletic education programs.

Even though a final set of guidelines has been provided, not all athletic training programs may opt to utilize this information. Common barriers of ethics education such as lack of time, resources, and university personnel may continue to prevent programs from incorporating ethics training. In order to ensure that all programs are consistently offering ethics education, the CAATE must outline specific requirements and expectations to be met in order to maintain accreditation.

It is important to note that the phase placement timeline of the final set of guidelines is merely a suggestion that has not been tested to determine overall validity. The components of the 
timeline were organized based upon pedagogical phases discussed throughout current nursing ethics literature. As one of the more developed professions in ethics training, the nursing field provides excellent insight into curriculum parameters and pedagogical techniques for ethics education. In a separate study, the components of the final set of guidelines should be compared to curriculums of nursing education programs and other healthcare professions. This will ensure that implementation of ethics material is supported by evidence-based findings throughout current ethics literature.

Limitations

A limitation to this study is that there were ten participants in the first round, and only five participants in the second round. It was a lengthy questionnaire, and participants may have not had the time to complete it for the second round. The inclusion criteria for this study were to include athletic training educators and medical ethics educators with at least five years of experience. The first round was sent out in early February, when educators are occupied with spring semester courses. The second round was sent out early March, when professors are preparing for mid-term assignments and exams, thus, meaning very little time to complete additional tasks outside of professional responsibilities, which likely contributed to the drop outs.

Another limitation in this study, based on the modified Delphi Technique, is that selection bias can occur. The participants can see responses from the first round and change responses based on what other participants selected. There can be pressure to conform after the participants see what responses were selected in the first round. The Delphi Technique also has limitations because of participant selection, and the fact the researcher cannot control the participants' expertise. ${ }^{19,21,22}$ Results cannot be generalized beyond the panel of experts specific 
to this study, as the findings are based uniquely on the opinions of those completing the questionnaire.

\section{CONCLUSION}

The original return to the classroom protocol contained 58 questions. After the second round, 38 components were favored highly. Two components were added to the final set of guidelines based on write-in comments from the panel, for a total of 40 components. The responses by the panel of experts allowed for the development of guidelines for ethics education in undergraduate athletic training programs. The information gained by the two rounds of questionnaires can assist athletic training educators when incorporating ethics curriculum into undergraduate athletic training programs. The areas identified could also potentially help athletic training educators to design an ethics course if their program does not currently provide ethics training. Since there is very limited information on ethics education for undergraduate athletic training programs, this set of guidelines could serve as a basis for development of an even more concise, yet complete, athletic training ethics course curriculum. 


\section{REFERENCES}

1. Mahajan R, Aruldhas B, Sharma M, Badyal D, Singh T. Professionalism and ethics: A proposed curriculum for undergraduates. Int J App Basic Med Res. 2016;6(3):157-163.

2. Williams J. Medical Ethics Manual. Cedex, France: The World Medical Association; 2015: 733.

3. Merriam-Webster's Dictionary. https://www.merriam-webster.com/dictionary/morality. Published 2016. Accessed October 16, 2016.

4. Filip I, Saheba N, Wick B, Radfar A. Morality and ethical theories in the context of human behavior. Ethics \& Medicine: Int J Bioethics. 2016;32(2):83-87.

5. Begley A. Facilitating the development of moral insight in practice: teaching ethics and teaching virtue. Nursing Philosophy. 2006;7(4):257-265.

6. Noddings N. Educating Moral People: A caring alternative to character education. Christ Higher Ed. 2005;4(1):71-73.

7. Williams J. Teaching ethics to athletic training students from CAATE accredited undergraduate athletic training education programs. ProQuest. 2008; 97-112.

8. Bandman EL. Bandman B. Nursing ethics through the life span. Upper Saddle River. NJ: Prentice Hall; 2002.

9. Martakis K, Czabanowska K, Schröder - Bäck P. Teaching ethics to pediatric residents: a literature anaylsis and synthesis. Klin Padiatr 2016; 228: 263-269.

10. Baykara Z, Demir S, Yaman S. The effect of ethics training on students recognizing ethical violations and developing moral sensitivity. Nursing Ethics. 2015;22(6):661-675.

11. Gold S, Chenoweth E, Zaleski J. Character matters: How to help our children develop good judgment, integrity, and other essential virtues. Publishers Weekly. 2003; 250(48):48.

12. National Athletic Trainers' Association Code of Ethics. http://www.nata.org/membership/about-membership/member-resources/code-of-ethics. Revised 2016. Accessed October 21, 2016.

13. Swisher L, Nyland J, Klossner D, Beckstead J. Ethical issues in athletic training: a foundational descriptive investigation. Athl Ther Today. 2009;14(2):3-9.

14. Curtis N, Helion J. Student athletic trainer perceptions of clinical supervisor behaviors: a critical incident Study. J Athl Train. 1998;33(3):249. 
15. Ediger M. Teaching clinical ethics using the four topic method. Int J Athl Ther Train. 2015;20(6):10-13.

16. O'Brien CW. Instilling foundational behaviors of professional practice in undergraduate athletic training students: a grounded theory study. ProQuest. 2011; 50-53.

17. National Athletic Trainers' Association. Job settings. https://www.nata.org/about/athletictraining/job-settings. Published 2016. Accessed December 11, 2016.

18. Murphy MK, Black N, Lamping DL, McKee CM, Sanderson CFB, Askham J, Marteau T. Consensus development methods and their use in clinical guideline development. Health Technol Assess. 1998;2(3):i-iv, 1-88.

19. Sandrey M, Bulger S. The delphi method: an approach for facilitating evidenced based practice in athletic training. Athl Train Ed J;2008;3(3)

20. Ziglio E. The delphi method and its contribution to decision-making. In Adler M, Ziglio E, eds. Gazing into the Oracle: The Delphi Method and its Application to Social Policy and Public Health. Bristol, PA: Jessica Kingsley Publisher;1996:3-33.

21. Raghav P, Kumar D, Bhardwaj P. Experience of delphi technique in the process of establishing consensus on core competencies. Int J App Basic Med Res. 2016;6(3):191-194.

22. Sahakian CE. The delphi method. Skokie, IL: The Corporate Partnering Institute;1997.

23. Brady S. Utilizing and adapting the delphi method for use in qualitative research. Int J Qual Methods. 2015;14(5):1-6.

24. Elliott RL. Introduction to medical ethics and professionalism. https://medicine.mercer.edu/ethics/resources/ Published 2016. Accessed December 14, 2016.

25. Miles SH, Lane LW, Bickel J, Walker RM, Cassel CK. Medical ethics education: coming of age. Acad Med. 1989;64:705-14.

26. Pariseau-Legault P, Lallier M. Constructing an ethical training for advanced nursing practice: an interactionist and competency-based approach. $J$ Nursing Ed. 2016;55(7):399-402.

27. Brockett M. Ethics, moral reasoning and professional virtue in occupational therapy education. Can J Occupat Ther 1996;63: 197-205.

28. Numminen O, Leino-Kilpi H, van der Arend A, Katajisto J. Nurse educators' teaching of codes of ethics. Nurse Ed Today. 2010;30(2):124-131.

29. Hudon A, Lalibert M, Ehrmann Feldman D. What place for ethics? An overview of ethics teaching in occupational therapy and physiotherapy programs in Canada. Disability \& Rehabil. 2014;36(9):775-780. 
30. Liaison Committee on Medical Education. Functions and structure of a medical school: standards for accreditation of medical education programs leading to the MD degree.

LCME®; 2016: 11. 


\section{APPENDICES}




\section{APPENDIX A}

\section{THE PROBLEM}

\section{Research Questions}

Ethics, the study of morality, involves the continual examination of moral decisionmaking and human behavior. ${ }^{1,2}$, More specifically, morality measures the weight of a belief or decision based upon moral "goodness" or "badness.", Filip et al. ${ }^{4}$ described morality as the foundation of a civilization, creating the standard for societal rules and laws. Within this ideology, every aspect of a society is affected by its members' accepted beliefs and behaviors. ${ }^{4}$

Despite the need for ethics, an even more critical factor is in the incorporation of ethics into education. Originating from the ideology of ancient Greek philosopher Aristotle, ethics education begins with the development of practical wisdom, or the ability to interpret and deliberate in ethical situations. ${ }^{5}$ Furthermore, Aristotle determined that maturity and experience are needed to establish practical wisdom. ${ }^{5}$ Noddings et al. ${ }^{6}$ elaborated further by developing the model of moral education through modeling, dialogue, practice, and confirmation. In short, students must be expected to practice moral decision-making and be guided through careful instruction by mentors. $^{7}$

Ethics education has evolved over time and varies with each professional program. Healthcare providers are frequently called to resolve difficult situations, sometimes not easily answered by scientific knowledge or methods. Bandman et al. ${ }^{8}$ recognized the high risk for moral concerns in the medical field. "Moral problems arise whenever and wherever there is a possibility of doing good or harm to someone."

Medical ethics, a branch of ethics study, deals with ethical concerns that arise within medical practice. ${ }^{2}$ Beginning in the early 1980 's, medical ethics education greatly evolved from 
a topic once deemed as unnecessary curriculum. ${ }^{9}$ Today, professional education programs for medical, nursing, and allied health disciplines have taken notice to the need for medical ethics education.

Ethics courses vary in the medical and nursing fields. In 2004 study, 125 U.S. medical schools were mailed a questionnaire pertaining to training within a larger course. ${ }^{31}$ However, the study also determined that medical ethics education varies in each program and does not follow a standardized course curriculum. ${ }^{31}$ Nursing education programs not only incorporate the American Nurses Association (ANA) Code of Ethics, but also individual courses in philosophical study. ${ }^{32}$ Demographic studies on nursing program curriculums are limited, however, after vigorous review of the current literature, nursing education programs utilize individual ethics courses more often than other health professions.

Allied health professions fare better or are limited as to incorporation of ethical training. A study conducted by the American Physical Therapy Association (APTA) concluded that out of 95 programs, 96 percent included ethics learning within the program curriculum. ${ }^{29}$ Later in 2000 , The Journal of Physical Therapy continued to urge the need for additional ethics education and a consistent amount of training time. ${ }^{29}$ The same author investigated Canadian Occupational Therapy (OT) education programs and determined a similar result. While many of the curriculums covered code of ethics materials, very little training was incorporated to help students develop ethical decision-making skills. ${ }^{27}$

In conjunction with other healthcare professions, the athletic training (AT) profession also lacks a strong foundation of moral and ethical education for its members. Since 2007, much of the literature has determined a need for recognition and resolution of ethical situations in the AT profession. ${ }^{7,13-15}$ Existing demographic studies suggest areas of improvement for athletic 
training education program (ATEP) ethics curriculum, however, little has been accomplished within the past nine years. ${ }^{7,16}$

William's 2007 survey determined that only 12 out of 106 AT educators reported offering a stand-alone ethics course to meet the Commission on Accreditation of Athletic Training Education (CAATE) requirements. Participants of the same survey also stated that ethics teaching is harshly limited in the classroom and clinical settings. Of participants surveyed, 39 percent reported zero hours of ethics teaching each semester, while 83 percent reported a maximum of only nine hours per semester. ${ }^{7}$

The Professional Education Council (PEC) of the National Athletic Trainers' Association (NATA) released a fifth edition of the Athletic Training Education Competencies (Competencies) in 2011, with a new edition to be released in $2016 .{ }^{33}$ The fifth edition Competencies provide program educators with required learning objectives in eight content areas. ${ }^{33}$ However, the Professional Development and Responsibility (PDR) content area provided a limited explanation of the expected education for ethical decision-making under PDR Objective No. 5 .

The objective stated that educators should, "Access, analyze, and differentiate between the essential documents of the national governing, credentialing, and regulatory body, including, but not limited to, the NATA Athletic Training Educational Competencies, the BOC Standards of Professional Practice, the NATA Code of Ethics, and the BOC Role Delineation Study/Practice Analysis."

While other content areas of the Competencies are satisfied and included in specific program course material, such as Therapeutic Modalities or Orthopedic Injury Assessment I and II, ethics courses are rarely incorporated into CAATE accredited ATEPs. ${ }^{7}$ More importantly, 
current literature has not addressed specific guidelines needed to formulate an appropriate ethics curriculum for the undergraduate ATEP setting.

Therefore, based on the information presented, the original research questions raised:

Research Questions:

1. Can a course be implemented for ethics training?

2. What specific components should be included in ethics curricula?

3. By what method should an ethics-training course be delivered to AT students?

Experimental Hypotheses

The original experimental hypotheses were:

1. There will be a consensus of the participants (75\%) in the study and a mean score of 4 on curriculum components within an athletic training ethics course.

2. There will be a consensus of the participants (75\%) in the study and a mean score of 4 on athletic trainer misconduct within the workplace setting.

3. There will be a consensus of the participants (75\%) in the study and a mean score of 4 on ethics competencies within an athletic training ethics course.

4. There will be a consensus of the participants (75\%) in the study and a mean score of 4 on educational methods for teaching athletic training ethics objectives.

5. There will be a consensus of the participants (75\%) in the study and a mean score of 4 on presentation of curriculum.

6. There will be a consensus of the participants (75\%) in the study and a mean score of 4 on program requirements for student completion of the ethics course.

Assumptions

1. Participants will answer all surveys honestly and to the best of their ability.

2. The questionnaires being used are valid and reliable.

3. Participants will return questionnaires completed in entirety.

4. Participants will have knowledge regarding ethics education. 


\section{Delimitations}

1. This study utilized participants from multiple educational backgrounds and institutions and therefore cannot be generalized to any one population.

2. Due to the individual format of courses in each academic institution, the results of this study can only be used as guidelines.

Operational Definitions

1. Autonomy- a term meaning independence, allows each patient to exercise the right to make decisions about his or her own body. ${ }^{24}$

2. Beneficence- employing methods of care that promote the overall welfare of the patient. ${ }^{24}$

3. Consensus- a mean score of four or 75 percent consensus of "strongly agree" or "agree". 19

4. Ethics- the study of moral decision-making and human behavior. ${ }^{2}$

5. Ethical decision making skills- the ability to recognize difficult situations and to deal with them in a rational and principled manner. ${ }^{2}$

6. Ethics education- the nurturing of practical wisdom and excellence of character. ${ }^{5}$

7. Morality- measures the weight of a belief or decision based upon moral "goodness" or "badness." 3

8. Medical ethics- ethical concerns that arise within medical practice. ${ }^{2}$

9. NATA Code of Ethics- the principles of ethical behavior that should be followed in the practice of athletic training. ${ }^{12}$

10. Nonmaleficence- "to do no harm.", 24

11. Practical wisdom- the ability to interpret and deliberate in ethical situations. ${ }^{5}$

12. Social justice- states that each patient should receive the same benefits and risks in medical care, regardless of socioeconomic status, race, or gender. ${ }^{24}$

\section{Limitations}

1. The Modified Delphi Technique requires a small sample size of participants. 
2. The Modified Delphi Technique is subject to selection bias.

3. The results of this study are not generalizable due to the selection of participants based on job setting and educational background.

4. The questions in the questionnaire may be misunderstood.

5. The busy work environment of athletic training professionals and educators may deter the ability of the participants to complete the survey to best of their ability.

Significance of the Study

Studying factors to formulate educational guidelines is significant because ethics education in the AT field is minimal. Based on review of the literature, athletic training students receive little-to-no ethics training throughout the course of undergraduate programs. Students who do receive ethics education oftentimes complete general ethics courses before applying to AT programs, but do not continue ethics education after entering formal AT courses.

Establishing specific guidelines for ethics education will stem from the understanding of effective pedagogical techniques used by experts in ethics education and applicable medical decision-making resources. This would help AT educators and preceptors to provide students with consistent, organized instruction for managing potential ethical concerns that may arise in medical practice.

Besides the benefits that can be provided to AT student education, patients will benefit from this study as well. Patients depend upon ATs to make critical decisions for immediate and future health concerns. Cultivating ethically sound ATs that are prepared to exude professional behavior and principled decision-making will only improve the standard of patient care. Instilling appropriate, ethical behavior will also help to prevent physical, emotional, or mental harm to athletes or patients under the care of a certified AT. 
After developing ethics educational guidelines, the information could be utilized to create a structured ethics course. The future creation of an ethics course could be disseminated through multiple outlets, including online workshops, educator conferences, and journal publications. Supplying ethics training through online workshops would provide a direct and accessible platform for immediate distribution of the information. Further presentation of this study's findings may be incorporated into educator conferences and journal publications to better prepare educators to implement ethics training within athletic training education programs. 


\section{APPENDIX B}

\section{REVIEW OF THE LITERATURE}

Introduction

Ethics, the study of morality, involves the continual examination of moral decisionmaking and human behavior. ${ }^{1,2}$ More specifically, morality measures the weight of a belief or decision based upon moral "goodness" or "badness." ${ }^{3}$ Filip et al. ${ }^{4}$ described morality as the foundation of a civilization, creating the standard for societal rules and laws. Within this ideology, every aspect of a society is affected by its members' accepted beliefs and behaviors. ${ }^{4}$

Despite the need for ethics, an even more critical factor is in the incorporation of ethics into education. Originating from the ideology of ancient Greek philosopher Aristotle, ethics education begins with the development of practical wisdom, or the ability to interpret and deliberate in ethical situations. ${ }^{5}$ Furthermore, Aristotle determined that maturity and experience are needed to establish practical wisdom. ${ }^{5}$ Noddings et al ${ }^{6}$ elaborated further by developing the model of moral education through modeling, dialogue, practice, and confirmation. In short, students must be expected to practice moral decision-making and be guided through careful instruction by mentors. ${ }^{7}$ This literature review will discuss ethics education, ethics curriculum in the allied health professions and athletic training, and the Modified Delphi Technique.

\section{Ethics Education}

Ethics education has evolved over time and varies with each professional program. Healthcare providers are frequently called to resolve difficult situations, sometimes not easily answered by scientific knowledge or methods. Bandman et al. ${ }^{8}$ recognized the high risk for moral concerns in the medical field. "Moral problems arise whenever and wherever there is a possibility of doing good or harm to someone." 
Medical ethics, a branch of ethics study, deals with ethical concerns that arise within medical practice. ${ }^{2}$ Before understanding the complex background of medical ethics, one must understand the ethical principle of "autonomy". Autonomy, a term meaning independence, allows each patient to exercise the right to make decisions about his or her own body. ${ }^{24} \mathrm{~A}$ patient's right to autonomy influences decision-making skills by driving medical professionals to place patient desires at the forefront of medical decisions and actions. Elliott ${ }^{24}$ discusses a second principle of medical ethics, termed as "beneficence". Clinicians act with beneficence by employing methods of care that promote the overall welfare of the patient. When questioning beneficence, the clinician must determine how the course of action will benefit the patient and if associated risks outweigh the benefits. ${ }^{24}$

Elliott ${ }^{24}$ defines the third principle of medical ethics as "nonmaleficence", meaning "do no harm." While somewhat obvious, this term helps clinicians to avoid actions that may inflict harmful consequences to the patient. Lastly, clinicians must abide by the fourth principle of medical ethics known as "social justice." Social justice states that each patient should receive the same benefits and risks in medical care, regardless of socioeconomic status, race, or gender. ${ }^{24}$

Beginning in the early 1980 's, medical ethics education greatly evolved from a topic once deemed as unnecessary curriculum. ${ }^{9}$ According to Baykara et al., ${ }^{10}$ ethics education is, "A process aiming to enable the professionals working in the healthcare field to conceive the role of moral values in their relations with individuals to whom they serve, the society they live in, colleagues, and other healthcare disciplines and the significance of such values in their professional identity."

At the forefront of moral education, healthcare providers must develop moral sensitivity in their medical practice. ${ }^{10}$ Moral sensitivity is one's ability to recognize ethical problems and 
manage the situations in an ethical manner. ${ }^{10}$ This premise is highly valuable in ethical decisionmaking, for it serves as the driving force behind one's ambition to implement ethical practice. ${ }^{10}$ Gold et al. ${ }^{11}$ seconded this ideology by affirming that students must learn to provide best practice through "moral knowing and feeling". This allows students to develop empathy for the individuals that they care for.

Further dissecting the constructs of moral education, Noddings et al. ${ }^{6}$ identified four main components including modeling, dialogue, practice, and confirmation. ${ }^{6,7}$ Modeling educates others about ethical care through an outward expression of acceptable behaviors, or in other words, "leading by example." Health care educators who express high professional and moral standards impress upon students to follow suit. At the center of Nodding's care model of moral education, dialogue allows the instructor and student to develop a trusting and honest relationship. By openly discussing ethical situations, students are educated on the importance of effective communication in the workplace. For the practice of moral decision-making, students must be allowed to apply the objectives of moral education by caring for others. Throughout this process, the mentor should continually provide confirmation to praise the student for good behaviors or provide constructive correction for bad behaviors.

Ethics Curriculum in the Allied Health Professions

Today, professional education programs for medical, nursing, and allied health disciplines have taken notice to the need for medical ethics education. In 2004 study, 125 U.S. medical schools were mailed a questionnaire to investigate the programs' descriptions of medical ethics curricula. ${ }^{31}$ Seventy-eight percent of participating schools reported incorporating ethics into larger, introductory courses. ${ }^{31}$ While the study determined that medical ethics education varies in each program, the authors identified several common barriers to ethics education 
including: lack of time in the curriculum, lack of qualified professors, and lack of professor availability. ${ }^{31}$

Upon further investigation, the Liaison Committee on Medical Education's standards for ethics education are as follows: "The faculty of a medical school ensure that the medical curriculum includes instruction for medical students in medical ethics and human values both prior to and during their participation in patient care activities and requires its medical students to behave ethically in caring for patients and in relating to patients' families and others involved in patient care. ${ }^{\prime 30}$ Although non-specific language outlines the expectations for medical ethics curriculum, several authors have attempted to provide a set of teaching goals and objectives.

Miles et al. ${ }^{25}$ consider the overall goals of an undergraduate medical ethics curriculum to consist of the following factors: (Table B1)

Table B1. Overall Goals of an Undergraduate Medical Ethics Program

- To enable physicians to examine and affirm their own personal and professional moral commitments.

- To teach physicians to recognize the humanistic and ethical aspects of medical careers.

- To equip physicians with a foundation of philosophical, social, and legal knowledge.

- To enable physicians to employ this knowledge in clinical reasoning.

- To equip physicians with the interactional skills needed to apply this insight, knowledge, and reasoning to human clinical care.

Miles et al. ${ }^{25}$ also stated that "the final goal of medical ethics education is to endow physicians with 'practical wisdom,' an informed ability to realize values in clinical management." This statement parallels with Aristotle's belief that students must grasp practical wisdom in order to interpret and deliberate in ethical situations. ${ }^{5}$ 
Nursing education programs not only incorporate the American Nurses Association (ANA) Code of Ethics, but also individual courses in philosophical study. ${ }^{32}$ Demographic studies on nursing program curriculums are limited, however, after vigorous review of the current literature, nursing education programs utilize individual ethics courses more often than other health professions. Baykara et al. ${ }^{10}$ reported that 78.9 percent of nurses who participated in the Moral Sensitivity Questionnaire testified to attaining their knowledge of moral and ethical conduct throughout their nursing education.

A questionnaire conducted by Numminen et al. ${ }^{28}$ found that out of 154 nursing educators, 85 and 72 percent of respondents utilized lecture and discussion-style teaching methods for ethic course curriculum. Pariseau-Legault et al. ${ }^{26}$ examined a competency-based approach to help advanced nursing students enhance their abilities by strengthening moral and professional integrity, avoiding moral distress, justifying difficult ethical decisions, and collaborating with other health professionals. The authors found this method to be more applicable in the real-world setting, versus teaching nurses to utilize abstract principles in ethical situations. ${ }^{26}$

For pedagogical application, Pariseau-Legault et al. ${ }^{26}$ utilized the Six-Step Ethical Decision-Making Framework for Advanced Nursing Practice. The step-wise approach required groups of students to analyze and deliberate in specific case studies, beginning with Step 1: Building moral integrity. After reading the case scenario, each group practiced developing ethical sensibility by identifying the personal, professional, and societal values involved in the situation. Identifying specific values allowed students to determine if their judgment was consistently based upon a set of personal beliefs. ${ }^{26}$

Steps 2, 3, and 4 allowed students to conduct a factual evaluation of the situation, discuss specific legal consequences, and identify relevant ethical principles, respectively. Conducting 
Steps 2-4 was vital in helping students to recognize important legal obligations and utilize scientific knowledge in the decision-making process. ${ }^{26}$

Step 5: Development of deliberative competencies, assisted students in generating a plan of action through group collaboration and consensus building. Each group identified common goals, constructed possible scenarios for resolving the specific situation, and selected a final course of action. Lastly, Step 6: Evaluating the outcomes of the deliberative process, required students to analyze situational outcomes and discuss methods of improvement for future scenarios. $^{26}$

A study conducted by the American Physical Therapy Association (APTA) concluded that out of 95 programs, 96 percent included ethics learning within the program curriculum. ${ }^{29}$ Later in 2000, The Journal of Physical Therapy continued to urge the need for additional ethics education and a consistent amount of training time. ${ }^{29}$ The same author investigated Canadian Occupational Therapy (OT) education programs and determined a similar result. While many of the curriculums covered code of ethics materials, very little training was incorporated to help students develop ethical decision-making skills. ${ }^{27}$

Ethics Curriculum in Athletic Training

In conjunction with other healthcare professions, the athletic training (AT) profession also lacks a strong foundation of moral and ethical education for its members. The National Athletic Trainers' Association (NATA) Code of Ethics (Table B2) provides practicing athletic trainers with an outline of the association's expectations and recommendations for appropriate behavior within the athletic training profession. ${ }^{12}$ Even with outlined expectations, athletic trainers continue to encounter difficult situations, or "grey areas," that are not easily identified or resolved using the non-specific language of the NATA Code of Ethics (Table B2). 
Since 2007, much of the literature has determined a need for recognition and resolution of ethical situations in the AT profession. ${ }^{7}{ }^{13-15}$ Existing demographic studies suggest areas of improvement for athletic training education program (ATEP) ethics curriculum, however, little has been accomplished within the past nine years. ${ }^{7,16}$

William's 2007 survey determined that only 12 out of 106 AT educators reported offering a stand-alone ethics course to meet the Commission on Accreditation of Athletic Training Education (CAATE) requirements. ${ }^{7}$ Participants of the same survey also stated that ethics teaching is harshly limited in the classroom and clinical settings. Of participants surveyed, 39 percent reported zero hours of ethics teaching each semester, while 83 percent reported a maximum of only nine hours per semester. ${ }^{7}$

According to the 2012 Standards for the Accreditation of Professional Athletic Training Programs, "The purpose of the Commission on Accreditation of Athletic Training Education (CAATE) is to develop, maintain, and promote appropriate minimum education standards for quality for athletic training programs.”

The Professional Education Council (PEC) of the National Athletic Trainers' Association (NATA) released a fifth edition of the Athletic Training Education Competencies (Competencies) in 2011, with a new edition to be released in $2016 .{ }^{33}$ The fifth edition Competencies provide program educators with required learning objectives in eight content areas. ${ }^{33}$

However, the Professional Development and Responsibility (PDR) content area provided a limited explanation of the expected education for ethical decision-making under PDR Objective No. 5. The objective stated that educators should, "Access, analyze, and differentiate between the essential documents of the national governing, credentialing, and regulatory body, 
including, but not limited to, the NATA Athletic Training Educational Competencies, the BOC Standards of Professional Practice, the NATA Code of Ethics, and the BOC Role Delineation Study/Practice Analysis." ${ }^{, 33}$

While other content areas of the Competencies are satisfied and included in specific program course material, such as Therapeutic Modalities or Orthopedic Injury Assessment I and II, ethics courses are rarely incorporated into CAATE accredited ATEPs. ${ }^{7}$ More importantly, current literature has not addressed specific pedagogical techniques needed to teach ethics courses or an appropriate curriculum for the undergraduate ATEP setting.

Furthermore, athletic training educators play a large role in preparing undergraduate athletic training students to act professionally and ethically within clinical practice. ${ }^{7}$ Athletic training educators fall into three categories in the educational program hierarchy: athletic training education Program Director (PD), Clinical Education Coordinator (CEC), and Preceptor. ${ }^{7,16}$

The athletic training education Program Director is responsible for planning, development, implementation, delivery, documentation, and assessment over all areas of program curriculum. ${ }^{33}$ The Program Director also upholds administrative and supervisory responsibility in maintaining the Commission on Accreditation of Athletic Training Education (CAATE) Standards. ${ }^{33}$ The Clinical Education Coordinator ensures student clinical progression, evaluation of clinical sites and student performance, and preceptor training and evaluation. ${ }^{33}$ Lastly, the Preceptor works to supervise athletic training students during clinical education, provide opportunities for the student to develop clinical proficiencies and decision-making skills during actual patient care, and provide instruction and assessment of the current knowledge, skills, and clinical abilities designated by the Commission. ${ }^{33}$ 
Throughout the duration of a professional athletic training program, the PD, CEC, and Preceptor(s) significantly affect student professional growth and development through acceptance, nurturing, and most importantly, modeling. ${ }^{16}$ While the PD and CEC provide formal education as full-time faculty members, the Preceptor demonstrates decision-making skills through real-world experiences with actual human subjects. With such a large role in student education outcomes, one could question the need for athletic training educators to complete additional training or continuing education to practice ethics training pedagogical skills. The Modified Delphi Technique

Due to insufficient information about ethics education in athletic training, the Delphi Method was recruited as the primary data collection tool of this study. Unlike the traditional scientific method, the Delphi Method does not attempt to create new knowledge, but investigates the current wisdom and expertise of a panel of participants. ${ }^{18,19}$ As described by Ziglio, ${ }^{20}$ the Delphi Method is "a structured process for collecting and distilling knowledge from a group of experts by means of a series of questionnaires interspersed with controlled opinion feedback." Most importantly for this study, the Delphi Method has been utilized for nearly 50 years and is praiseworthy for its use of developing educational curriculum. $^{21}$

The Delphi Method delivers two rounds of questionnaires to a selected panel of experts. Unlike other data collection methods, the panel of experts does not assist in formulating the questionnaire, but attempts to answer each question from background knowledge and expertise. ${ }^{19}$

The Delphi Method provides multiple advantages during the research process. First and foremost, the greatest advantage is its ability to motivate the involved participants. ${ }^{19}$ The participants collectively adopt the problem in question and work together to claim a uniform decision. ${ }^{22}$ Compared to traditional group meetings, the Delphi Method also eliminates 
influential personalities and allows each participate to answer with anonymity. ${ }^{18-22}$ Lastly, the Delphi Method provides inexpensive data collection through electronic questionnaires that are easily distributed to participants in a time-efficient manner. ${ }^{23}$

Summary

Ethics is complex study of human behaviors and moral decision-making. With a need for ethics in society, ethics education has evolved over time, specifically in medical education programs. Healthcare providers are frequently called to resolve difficult situations, increasing the need for ethically sound clinicians in the medical workforce. Athletic trainers, a healthcare representative for athletes and the athletic population, are not immune to handling ethical dilemmas while in practice. The need for ethics education in the athletic training profession is significant, requiring the formulation of specific curriculum in undergraduate athletic training programs. Other allied health professions provide suggested objectives for ethics education, however, no uniform consensus has been found for students receiving training in the medical field. 
Table B2. National Athletic Trainers' Association Code of Ethics ${ }^{12}$

\section{MEMBERS SHALL PRACTICE WITH COMPASSION, RESPECTING THE RIGHTS, WELFARE, AND DIGNITY OF OTHERS}

1.1 Members shall render quality patient care regardless of the patient's race, religion, age, sex, ethnic or national origin, disability, health status, socioeconomic status, sexual orientation, or gender identity.

1.2. Member's duty to the patient is the first concern, and therefore members are obligated to place the welfare and long-term well-being of their patient above other groups and their own self-interest, to provide competent care in all decisions, and advocate for the best medical interest and safety of their patient at all times as delineated by professional statements and best practices.

1.3. Members shall preserve the confidentiality of privileged information and shall not release or otherwise publish in any form, including social media, such information to a third party not involved in the patient's care without a release unless required by law.

\section{MEMBERS SHALL COMPLY WITH THE LAWS AND REGULATIONS GOVERNING THE PRACTICE OF ATHLETIC TRAINING, NATIONAL ATHLETIC TRAINERS' ASSOCIATION (NATA) MEMBERSHIP STANDARDS, AND THE NATA CODE OF ETHICS}

2.1. Members shall comply with applicable local, state, federal laws, and any state athletic training practice acts.

2.2. Members shall understand and uphold all NATA Standards and the Code of Ethics.

2.3. Members shall refrain from, and report illegal or unethical practices related to athletic training.

2.4. Members shall cooperate in ethics investigations by the NATA, state professional licensing/regulatory boards, or other professional agencies governing the athletic training profession. Failure to fully cooperate in an ethics investigation is an ethical violation.

2.5. Members must not file, or encourage others to file, a frivolous ethics complaint with any organization or entity governing the athletic training profession such that the complaint is unfounded or willfully ignore facts that would disprove the allegation(s) in the complaint.

2.6. Members shall refrain from substance and alcohol abuse. For any member involved in an ethics proceeding with NATA and who, as part of that proceeding is seeking rehabilitation for substance or alcohol dependency, documentation of the completion of rehabilitation must be provided to the NATA Committee on Professional Ethics as a requisite to complete a NATA membership reinstatement or suspension process.

\section{MEMBERS SHALL MAINTAIN AND PROMOTE HIGH STANDARDS IN THEIR PROVISION OF SERVICES}

3.1. Members shall not misrepresent, either directly or indirectly, their skills, training, professional credentials, identity, or services.

3.2. Members shall provide only those services for which they are qualified through education or experience and which are allowed by the applicable state athletic training practice acts and other applicable regulations for athletic trainers.

3.3. Members shall provide services, make referrals, and seek compensation only for those services that are necessary and are in the best interest of the patient as delineated by professional statements and best practices. 
3.4. Members shall recognize the need for continuing education and participate in educational activities that enhance their skills and knowledge and shall complete such educational requirements necessary to continue to qualify as athletic trainers under the applicable state athletic training practice acts.

3.5. Members shall educate those whom they supervise in the practice of athletic training about the Code of Ethics and stress the importance of adherence.

3.6. Members who are researchers or educators must maintain and promote ethical conduct in research and educational activities.

4. MEMBERS SHALL NOT ENGAGE IN CONDUCT THAT COULD BE CONSTRUED AS A CONFLICT OF INTEREST, REFLECTS NEGATIVELY ON THE ATHLETIC TRAINING PROFESSION, OR JEOPARDIZES A PATIENT'S HEALTH AND WELL-BEING.

4.1. Members should conduct themselves personally and professionally in a manner that does not compromise their professional responsibilities or the practice of athletic training.

4.2. All NATA members, whether current or past, shall not use the NATA logo in the endorsement of products or services, or exploit their affiliation with the NATA in a manner that reflects badly upon the profession.

4.3. Members shall not place financial gain above the patient's welfare and shall not participate in any arrangement that exploits the patient.

4.4. Members shall not, through direct or indirect means, use information obtained in the course of the practice of athletic training to try and influence the score or outcome of an athletic event, or attempt to induce financial gain through gambling.

4.5. Members shall not provide or publish false or misleading information, photography, or any other communications in any media format, including on any social media platform, related to athletic training that negatively reflects the profession, other members of the NATA, NATA officers, and the NATA office. 


\section{APPENDIX C \\ ADDITIONAL METHODS}

Table C1. Initial E-mail Contact Letter

February 6, 2017

Your assistance and knowledge are needed!

You have been selected to participate in this research study based on your credentials and experience working in athletic training education or ethics education. Working as an athletic training educator or ethics educator qualifies you for this study. My name is Katie Cullen and I am a graduate student in the West Virginia University Graduate Athletic Training Program, along with my GA assignment at Waynesburg University. I will be conducting a study with the primary investigator, Michelle A. Sandrey, $\mathrm{PhD}, \mathrm{ATC}$, to fulfill requirements for a Master's thesis and to complete a Master's of Science degree in Athletic Training. All are affiliated with West Virginia University.

I am writing to seek your participation in my research study entitled "Development of Ethics Education Guidelines for Undergraduate Athletic Training Education Programs." The purpose of this study is to develop guidelines for ethics education in undergraduate athletic training programs. The intent is to use feedback from this questionnaire in conjunction with current literature to develop recommended learning objectives within an athletic training ethics course.

In order to accomplish this, I am asking for your expertise in this area. This is an excellent opportunity for you to take part in research that will improve the continuity of care that Certified Athletic Trainers provide through ethical practice.

This process will include two rounds of questionnaires. You will receive the round one questionnaire with demographic questions and write-in comments. Once the results have been analyzed, you will receive an updated second round questionnaire with first round results and write-in comments. It will take roughly 25 minutes to complete each questionnaire.

Your participation in this research is important, and will provide you with the opportunity to help develop guidelines for ethics education in undergraduate athletic training programs. Participation in this study is voluntary and will not affect your employment status. Your responses are completely confidential, and you are able to skip questions.

West Virginia University IRB has approved this research project, and acknowledgement is on file. If you are willing to participate, please respond to this email by including your email address. I would like to thank you in advance for your willingness to participate and share your medical ethics expertise. The survey will be sent through Qualtrics, so please be on the lookout for an email containing the survey.

Kind Regards,

Katie Cullen, LAT, ATC

kebarr@mix.wvu.edu 
Table C2. Initial Cover Letter for Round One

February 7, 2017

\section{Dear Participant,}

You have been selected to participate in this research study based on your credentials and experience working in athletic training education or ethics education. Working as an athletic training educator or ethics educator qualifies you for this study. My name is Katie Cullen and I am a graduate student in the West Virginia University Graduate Athletic Training Program, along with my GA assignment at Waynesburg University. I will be conducting a study with the primary investigator, Michelle A. Sandrey, PhD, ATC, to fulfill requirements for a Master's Thesis and to complete a Master's of Science degree in Athletic Training. All are affiliated with West Virginia University.

Your participation in this research is important, and will provide you with the opportunity to help develop a set of guidelines for ethics education in undergraduate athletic training programs. Participation in this study is voluntary and will not affect your employment status. Your responses are completely confidential and you are able to skip questions. West Virginia University IRB has approved this research project, and approval is on file.

The design behind this research is the Modified Delphi Technique. The process includes two rounds of online questionnaires. You will initially receive a link to round one questionnaire through Qualtrics. Answers will be recorded using a Likert scale of 5 being "strongly agree" and 1 being "strongly disagree." Questionnaire completion should take approximately 25 minutes. You will have the opportunity to provide feedback and additional comments at the end of each section. The second round of the Modified Delphi Technique involves reviewing the results of the first round questionnaire and provided write-in comments. Please go to the following website to complete the survey:

$\$\{1: / /$ SurveyLink?d=Take the survey $\}$

If you have any questions or concerns please contact me at kebarr@mix.wvu.edu. You can contact Michelle A Sandrey, PhD, ATC, Principal Investigator and Graduate Athletic Training Program Director at West Virginia University at msandrey@ wvu.edu. Thank you for your time and help with this project.

Sincerely,

Katie Cullen, LAT, ATC

Follow this link to the Survey:

$\$\{1: / /$ SurveyLink?d=Take the survey $\}$

Or copy and paste the URL below into your internet browser:

$\$\{1: / /$ SurveyURL $\}$

Follow the link to opt out of future emails:

$\$\{1: / / O p t O u t L i n k ? d=C l i c k$ here to unsubscribe $\}$ 
February 14, 2017

\section{Dear Participant,}

This is a reminder that the questionnaire on ethics training guidelines for undergraduate athletic training programs is due by February 20,2017. This is an excellent opportunity for you to take part in research to develop a set of guidelines for ethics education in undergraduate athletic training programs. I will be conducting this research study with the primary investigator Michelle A. Sandrey PhD, ATC to fulfill requirements for a Master's thesis and to complete an M.S. degree in Athletic Training.

For those of you who have already submitted your responses or are in the process, we apologize for this interruption and thank you for your participation.

We encourage all of you to take approximately 25 minutes to complete the questionnaire. Your expert opinion is very important as an athletic trainer educator or ethics educator! You will have the opportunity to provide feedback and add additional comments on ethics education guidelines to assistant athletic training educators. The $2^{\text {nd }}$ round of the Modified Delphi technique involves reviewing the 1 st round questionnaire results (mean scores and frequencies) and providing write-in comments. Again, you will select the response using the Likert scale provided. Please see the attached link below to participate in this survey.

This is a completely voluntary activity and all responses are guaranteed to be anonymous and confidential. Questions can be skipped, and you have the right to withdraw any data you submit at any time. Your job status will not be affected by failure to participate. West Virginia University IRB has acknowledgement on file.

If you have any questions or concerns please contact Katie Cullen by email at kebarr@mix.wvu.edu. You may also contact Dr. Michelle Sandrey, Principal Investigator and Graduate Athletic Training Program Director at West Virginia University, by email at msandrey@wvu.edu.

Thank you for your participation in this study!

Sincerely,

Katie Cullen, LAT, ATC

Follow this link to the Survey:

$\$\{1: / /$ SurveyLink?d=Take the survey $\}$

Or copy and paste the URL below into your internet browser:

$\$\{1: / /$ SurveyURL $\}$

Follow the link to opt out of future emails:

$\$\{1: / / O p t O u t L i n k ? d=C l i c k$ here to unsubscribe $\}$ 
March 1, 2017

Dear Participant,

This is a reminder that the second round questionnaire on the development of educational guidelines for ethics in athletic training is now available and due by March $13^{\text {th }}, 2017$.

This is an excellent opportunity for you to take part in research to develop a set of guidelines for ethics education in undergraduate athletic training programs. Your first round responses as an athletic training educator or ethics educator were informative and helpful in compiling this research. The second round questionnaire will be the final step in developing the ethics education guidelines. This is your opportunity to see the results of the first round, provide additional comments, and answer new questions formulated from the first round comments. Your final responses are very important and will be beneficial to help athletic training educators when teaching ethics-related curriculum. I will be conducting this research study with the primary investigator Michelle A. Sandrey PhD, ATC to fulfill requirements for a Master's research project and to complete an MS degree in Athletic Training.

For those of you who have already submitted your responses or are in the process, we apologize for this interruption and thank you for your participation. For those of you who no longer have the original information, please use the link below to access the questionnaire.

I encourage all of you to take a few minutes to complete the questionnaire using the Likert scale and add comments as you see fit. Your expert opinion is very important in developing these guidelines! This is a completely voluntary activity and all responses are guaranteed to be anonymous and confidential. Questions can be skipped, and you have the right to withdraw any data you submit at any time. Your job status will not be affected by failure to participate. West Virginia University IRB has acknowledgement on file.

If you have any questions or concerns please contact me at kebarr@mix.wvu.edu. You can contact Michelle A Sandrey, PhD, ATC, Principal Investigator and Graduate Athletic Training Program Director at West Virginia University at msandrey@wvu.edu. Thank you for your time and help with this project.

Sincerely,

Katie Cullen, LAT, ATC

Follow this link to the Survey:

$\$\{1: / /$ SurveyLink?d=Take the survey $\}$

Or copy and paste the URL below into your internet browser: $\$\{1: / /$ SurveyURL $\}$

Follow the link to opt out of future emails: \$\{l://OptOutLink?d=Click here to unsubscribe $\}$ 
March 6, 2017

Dear Participant,

This is a reminder that the questionnaire on the development of educational guidelines for ethics in athletic training is due by March $13^{\text {th }}, 2017$.

This is an excellent opportunity for you to take part in research to develop a set of guidelines for ethics education in undergraduate athletic training programs. Your first round responses as an athletic training educator or ethics educator were informative and helpful in compiling this research. The second round questionnaire will be the final step in developing the ethics education guidelines. This is your opportunity to see the results of the first round as well as the additional comments. Your final responses are very important and will be beneficial to help athletic trainers when teaching ethics-related curriculum. I will be conducting this research study with the primary investigator Michelle A. Sandrey $\mathrm{PhD}, \mathrm{ATC}$ to fulfill requirements for a Master's research project and to complete an MS degree in Athletic Training.

For those of you who have already submitted your responses or are in the process, we apologize for this interruption and thank you for your participation. For those of you who no longer have the original information, please follow the link below to complete the questionnaire.

I encourage all of you to take a few minutes to complete the questionnaire using the Likert scale and add comments. Your expert opinion is very important in developing these guidelines! This is a completely voluntary activity and all responses are guaranteed to be anonymous and confidential. Questions can be skipped, and you have the right to withdraw any data you submit at any time. Your job status will not be affected by failure to participate. West Virginia University IRB has acknowledgement on file.

If you have any questions or concerns please contact me at kebarr@mix.wvu.edu. You can contact Michelle A Sandrey, PhD, ATC, Principal Investigator and Graduate Athletic Training Program Director at West Virginia University at msandrey@wvu.edu. Thank you for your time and help with this project.

Thank you!

Katie Cullen, LAT, ATC

Follow this link to the Survey:

\$\{://SurveyLink?d=Take the survey\}

Or copy and paste the URL below into your internet browser: $\$\{1: / /$ SurveyURL $\}$ 
Instructions: Please complete the survey as honestly as possible and to the best of your ability. Please add any additional comments you have in the comment section following each category.

Demographics

1. What is your current title? (Select all that apply)
A. Athletic training program director
B. Athletic training clinical coordinator
C. Athletic training educator
D. Ethics educator
E. Ethics committee member (professional organization)
F. Ethics committee member (university organization)
G. Other

2. Have your served at any of the above positions for at least five years?
A. Yes
B. No

3. What is the highest education level you have accomplished?
A. BS/BA
B. $M S / M A$
C. $\mathrm{PhD}$
D. EdD
E. Other

4. Where is the primary setting where you work?
A. Division I University
B. Division II University
C. Division III University
D. Other

5. Are you a certified athletic trainer?
A. Yes
B. No education:
A. 0
B. 1-3
C. $4-6$
D. $7-10$
E. More than 10

C. I was once a certified athletic trainer, but no longer uphold the ATC credential

6. Number of presentations (national level i.e. NATA conference) in the area of ethics

7. Number of presentations (regional level i.e. district conference or meeting) in the area 
of ethics education:
A. 0
B. 1-3
C. 4-6
D. 7-10
E. More than 10

8. Number of presentations (local level i.e. school event) in the area of ethics education:
A. 0
B. 1-3
C. 4-6
D. $7-10$
E. More than 10

9. Number of peer-reviewed publications in the area of ethics education:
A. 0
B. 1-3
C. $4-6$
D. $7-10$
E. More than 10

10. Which type of educator is responsible for teaching medical ethics and moral decision-making in an athletic training education program? (Select all that apply)
A. Athletic training program director
B. Athletic training clinical coordinator
C. Athletic training preceptor
D. Ethics educator
E. Other

11. In your institution, how many hours per semester are students provided with ethics instruction?
A. No instruction is provided
B. 1-3 hours
C. 3-6 hours
D. 6-9 hours
E. 9-12 hours
F. $12+$ hours

12 . What is the best method to provide students with ethics-related course material? (Choose one)
A. Stand-alone college course
B. Stand-alone online college course
C. Topic or lesson within another college course
C. Professional conference
D. Online module
E. Published journal article 
Key: $\mathrm{SD}=$ strongly disagree; $\mathrm{D}=$ disagree; $\mathrm{N}=$ neutral; $\mathrm{A}=$ agree; $\mathrm{SA}=$ strongly agree

\section{CURRICULUM COMPONENTS}

\begin{tabular}{llllll}
\hline Question & SD (1) & D (2) & N (3) & A (4) & SA (5) \\
\hline 1. Students should know and understand the & & & & & \\
National Athletic Trainers' Association Code & & & & & \\
of Ethics.
\end{tabular}

2. Students should research the professional behavior standards of the state licensing board associated with their academic institution. (Example: West Virginia University AT students would research the West Virginia Athletic Training Licensing Board)

3. Students should know and understand their athletic training education program's code of ethics.

4. Students should know and understand the professional responsibilities of an athletic trainer.

5. Students should know and understand the ethical obligations of the athletic training profession to athletic and physically active populations.

6. Students should know the most relevant medical ethics history.

7. Students should understand the ethical concept of patient autonomy.

8. Students should understand the ethical concept of beneficence. (Beneficence is action that is done for the benefit of others)

9. Students should understand the ethical concept of nonmalficence. (Nonmaleficence means to "do no harm.")

10. Students should understand the ethical concept of patient informed consent.

11. Students should be able to clarify between personal, professional, and organizational values.

12. Students should practice examining and affirming their own personal and professional moral beliefs.

13. Students should practice examining the personal and professional moral beliefs of other people.

14. Students should understand and identify barriers to ethical practice. 
15. Students should be able to recognize situations involving unethical decision-making by themselves or others in the workplace.

16. Students should practice effective communication skills necessary to report ethical concerns.

17. Students should practice communicating with other fellow healthcare providers to resolve ethical situations.

18. Students should utilize ethical decision-making frameworks when formulating a plan of action for dealing with ethical situations.

19. Students should know and understand the professional and legal consequences of poor ethical decision-making in the workplace.

\section{Comments:}

\section{ATHLETIC TRAINER MISCONDUCT}

Question

20. Students should understand the common types of unethical athletic trainer conduct, including: sexual contact with patients and staff.

21. Students should understand the common types of unethical athletic trainer conduct, including: boundary conflicts (i.e. using position of power as AT to influence patient's decision-making)

22. Students should understand the common types of unethical athletic trainer conduct, including: economic self-interest.

23. Students should understand the common types of unethical athletic trainer conduct, including: substance abuse.

24. Students should understand the common types of unethical athletic trainer conduct, including: disruptive athletic trainer behavior.

\section{Comments:}

\begin{tabular}{|l|l|l|l|l} 
SD (1) & D (2) & N(3) & A(4) & SA(5) \\
\hline & & & & \\
\hline
\end{tabular}

\section{ETHICAL COMPETENCIES}

\begin{tabular}{|c|c|c|c|c|c|}
\hline Question & SD(1) & $\mathrm{D}(2)$ & $\mathrm{N}(3)$ & $\mathrm{A}(4)$ & $\overline{\mathrm{SA}}(5)$ \\
\hline $\begin{array}{l}\text { 25. Students should demonstrate ethical standa } \\
\text { that correspond with National Athletic } \\
\text { Trainers' Associate Code of Ethics. }\end{array}$ & & & & & \\
\hline $\begin{array}{l}\text { 26. Students should demonstrate the ability to } \\
\text { document a patient's informed consent. }\end{array}$ & & & & & \\
\hline
\end{tabular}


27. Students should demonstrate the ability to act appropriately if a patient is partially competent, or is incompetent to make treatment decisions.

28. Students should demonstrate the ability to act appropriately if a patient refuses treatment.

29. Students should demonstrate the ability to document a patient's refusal of treatment.

30. Students should demonstrate the ability to decide when it is ethically justified to withhold information from the patient.

31. Students should demonstrate the ability to decide when it is ethically justified to breach confidentiality (i.e. HIPAA regulations).

32. Students should demonstrate the ability to manage conflicting ethical opinions with a patient and/or his or her support group, in a professional manner.

33. Students should demonstrate the ability to deliver information and care to patients and their families in the event of a poor prognosis.

34. Students should demonstrate the ability to incorporate a team approach in dealing with ethical issues.

35. Students should demonstrate the ability to evaluate an employment contract for aspects that may be ethically incorrect.

36. Students should demonstrate the ability to conduct a consultation with an institutional ethics committee.

\section{Comments:}

\section{EDUCATIONAL METHODS}

\begin{tabular}{llllll}
\hline Question & SD (1) & D (2) & N (3) & A (4) & SA (5) \\
\hline 37. Ethical decision-making is most effectively & & & & &
\end{tabular}
taught through role-play.

38. Ethical decision-making is most effectively taught through scenario-based exercises.

39. Ethical decision-making is most effectively taught through reflective journaling.

40. Ethical decision-making is most effectively taught through mentoring.

41. Ethical decision-making is most effectively taught through modeling the behaviors of others.

42. Ethical decision-making is most effectively 
taught through clinical experience.

43. Ethical decision-making is most effectively taught through educational games (trivia, etc).

44. Ethical decision-making is most effectively taught through small group activities.

45. Ethical decision-making is most effectively taught through case study discussion in the classroom.

46. Ethical decision-making is most effectively taught through classroom presentations.

47. Ethical decision-making is most effectively taught through writing assignments.

48. Ethical decision-making is most effectively learned through writing research papers.

\section{Comments:}

\section{PRESENTATION OF CURRICULUM}

\section{Question}

SD (1)

$\mathrm{D}(2)$

N (3)

A (4)

49. Ethics training is best delivered in a standalone course.

50. Ethics training is best delivered as an objective within a larger course.

51. Ethics training is best delivered within an online module.

52. Ethics training is best delivered within a professional conference.

53. Ethics training is best delivered within journal publications.

\section{Comments:}

\section{PROGRAM REQUIREMENTS}

Question

SD (1)

D (2)

$\mathbf{N}(3)$

A (4)

SA (5)

54. Undergraduate athletic training programs should require all students to complete an ethics-related course before providing care to patients.

55. Undergraduate athletic training programs should require students to complete clinical competencies on ethics-related content, while completing clinical rotations.

56. Undergraduate athletic training programs should require students to complete yearly ethics-training modules before entering the clinical setting.

57. Educators who teach ethics-related curriculum should have background experience in ethics 
education.

58. Athletic training clinical preceptors should be required to complete ethics-training (designated by the athletic training education program) before they are approved to mentor students.

Comments: 
Instructions: Please complete the survey as honestly as possible and to the best of your ability. New questions have been added to some sections. Means and frequencies of first round responses have been added for your review. Please add any additional comments you have in the comment section following each category.

Key: $\mathrm{SD}=$ strongly disagree; $\mathrm{D}=$ disagree; $\mathrm{N}=$ neutral; $\mathrm{A}=$ agree; $\mathrm{SA}=$ strongly agree

\section{CURRICULUM COMPONENTS}

\begin{tabular}{|c|c|c|c|c|c|}
\hline$\overline{\text { Question }}$ & SD (1) & $\overline{D(2)}$ & $\overline{\mathrm{N}}(\mathbf{3})$ & A (4) & $\overline{\text { SA (5) }}$ \\
\hline $\begin{array}{l}\text { 1. Students should know and understand the } \\
\text { National Athletic Trainers' Association Code }\end{array}$ & & & & & \\
\hline
\end{tabular}

2. Students should research the professional behavior standards of the state licensing board associated with their academic institution. (Example: West Virginia University AT students would research the West Virginia Athletic Training Licensing Board)

3. Students should know and understand their athletic training education program's code of ethics.

4. Students should know and understand the professional responsibilities of an athletic trainer.

5. Students should know and understand the ethical obligations of the athletic training profession to athletic and physically active populations.

6. Students should know the most relevant medical ethics history.

7. Students should understand the ethical concept of patient autonomy.

8. Students should understand the ethical concept of beneficence. (Beneficence is action that is done for the benefit of others)

9. Students should understand the ethical concept of nonmalficence. (Nonmaleficence means to "do no harm.")

10. Students should understand the ethical concept of patient informed consent.

11. Students should be able to clarify between personal, professional, and organizational values.

12. Students should practice examining and 
affirming their own personal and professional

moral beliefs.

13. Students should practice examining the personal and professional moral beliefs of other people.

14. Students should understand and identify barriers to ethical practice.

15. Students should be able to recognize situations involving unethical decision-making by themselves or others in the workplace.

16. Students should practice effective communication skills necessary to report ethical concerns.

17. Students should practice communicating with other fellow healthcare providers to resolve ethical situations.

18. Students should utilize ethical decision-making frameworks when formulating a plan of action for dealing with ethical situations.

19. Students should know and understand the professional and legal consequences of poor ethical decision-making in the workplace.

\section{Comments:}

\section{ATHLETIC TRAINER MISCONDUCT}

Question

20. Students should understand the common types of unethical athletic trainer conduct, including: sexual contact with patients and staff.

21. Students should understand the common types of unethical athletic trainer conduct, including: boundary conflicts (i.e. using position of power as AT to influence patient's decision-making)

22. Students should understand the common types of unethical athletic trainer conduct, including: economic self-interest.

23. Students should understand the common types of unethical athletic trainer conduct, including: substance abuse.

24. Students should understand the common types of unethical athletic trainer conduct, including: disruptive athletic trainer behavior.

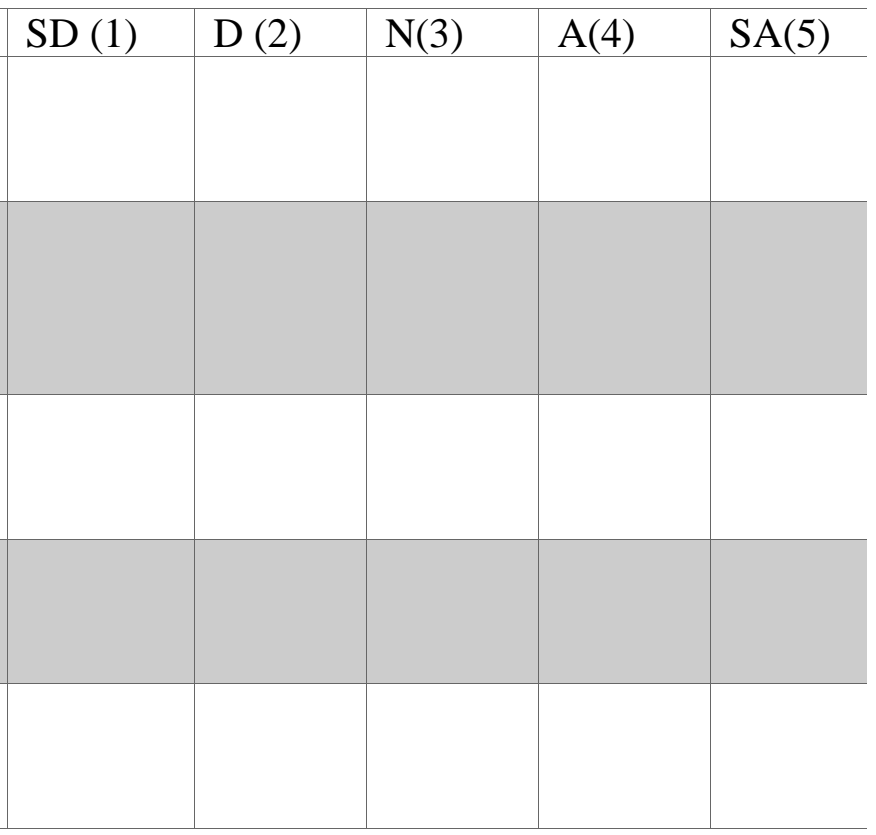

\section{Comments:}




\section{ETHICAL COMPETENCIES}

Question

25. Students should demonstrate ethical standards that correspond with National Athletic Trainers' Associate Code of Ethics.

26. Students should demonstrate the ability to document a patient's informed consent.

27. Students should demonstrate the ability to act appropriately if a patient is partially competent, or is incompetent to make treatment decisions.

28. Students should demonstrate the ability to act appropriately if a patient refuses treatment.

29. Students should demonstrate the ability to document a patient's refusal of treatment.

30. Students should demonstrate the ability to decide when it is ethically justified to withhold information from the patient.

31. Students should demonstrate the ability to decide when it is ethically justified to breach confidentiality (i.e. HIPAA regulations).

32. Students should demonstrate the ability to manage conflicting ethical opinions with a patient and/or his or her support group, in a professional manner.

33. Students should demonstrate the ability to deliver information and care to patients and their families in the event of a poor prognosis.

34. Students should demonstrate the ability to incorporate a team approach in dealing with ethical issues.

35. Students should demonstrate the ability to evaluate an employment contract for aspects that may be ethically incorrect.

36. Students should demonstrate the ability to conduct a consultation with an institutional ethics committee.

37. Preceptors should allow student to provide input when dealing with ethical situations that occur in the athletic training setting.

38. It is the preceptor's role to act as the primary decision-maker when dealing with ethical situations that occur in the athletic training setting.

39. Students should not act as the primary decision-maker when dealing with ethical 
situations that occur in the athletic training setting.

\section{Comments:}

\section{EDUCATIONAL METHODS}

\begin{tabular}{|c|c|c|c|c|c|}
\hline Question & SD (1) & D (2) & $\mathbf{N}(3)$ & $A(4)$ & SA (5) \\
\hline
\end{tabular}

41. Ethical decision-making is most effectively taught through scenario-based exercises.

42. Ethical decision-making is most effectively taught through reflective journaling.

43. Ethical decision-making is most effectively taught through mentoring.

44. Ethical decision-making is most effectively taught through modeling the behaviors of others.

45. Ethical decision-making is most effectively taught through clinical experience.

46. Ethical decision-making is most effectively taught through educational games (trivia, etc).

47. Ethical decision-making is most effectively taught through small group activities.

48. Ethical decision-making is most effectively taught through case study discussion in the classroom.

49. Ethical decision-making is most effectively taught through classroom presentations.

50. Ethical decision-making is most effectively taught through writing assignments.

51. Ethical decision-making is most effectively learned through writing research papers.

\section{Comments:}

\section{PRESENTATION OF CURRICULUM}

Question

52. Ethics training is best delivered in a standalone course.

53. Ethics training is best delivered as an objective within a larger course.

54. Ethics training is best delivered within an online module.

55. Ethics training is best delivered within a professional conference.

56. Ethics training is best delivered within journal publications.

\begin{tabular}{|l|l|l|l|l}
\hline SD (1) & D (2) & N (3) & A (4) & SA (5) \\
\hline & & & & \\
& & & & \\
& & & & \\
& & & & \\
& & & & \\
\hline
\end{tabular}




\section{Comments:}

\section{PROGRAM REOUIREMENTS}

Question

SD (1)

D (2)

N (3)

A (4)

SA (5)

57. Undergraduate athletic training programs should require all students to complete an ethics-related course before providing care to patients.

58. Undergraduate athletic training programs should require students to complete clinical competencies on ethics-related content, while completing clinical rotations.

59. Undergraduate athletic training programs should require students to complete yearly ethics-training modules before entering the clinical setting.

60. Educators who teach ethics-related curriculum should have background experience in ethics education.

61. Athletic training clinical preceptors should be required to complete ethics-training (designated by the athletic training education program) before they are approved to mentor students.

\section{Comments:}




\section{APPENDIX D}

\section{ADDITIONAL RESULTS}

Table D1.1. Certified Athletic Trainer Demographic Information_(n=7)

Screening Tool Component

Position of employment

Highest level of education

Currently uphold ATC credential

Primary work setting

Number of presentations (local)

Number of presentations (regional)

Number of presentations (national)

Number of publications in ethics education
Reponses

ATPD 28.57\%

$\mathrm{PhD}: 57.14 \%$

CC $28.57 \%$

ATE $57.14 \%$

Yes: $100 \% \quad$ No: $0 \%$

DI: $57.14 \% \quad$ DII: $14.29 \% \quad$ DIII: $28.57 \%$

Zero: $85.71 \% \quad 1-3: 14.29 \%$

Zero: $57.14 \% \quad 1-3: 42.86 \%$

Zero: $57.14 \% \quad 1-3: 42.86 \%$

Zero: $85.71 \% \quad 1-3: 14.29 \%$

*Athletic Training Program Director: ATPD Clinical Coordinator: CC Athletic Training Educator: ATE

*Doctorate of Philosophy: PhD Doctorate of Education: EdD Doctorate of Health Science: DHSc Master of Science: MS

*Division I University: DI Division II University: DII Division III University: DIII 
Table D1.2. Medical Ethics Educator Demographic Information (n=3)

Screening Tool Component

Highest level of education

Currently uphold ATC credential

Primary work setting

Number of presentations (local)

Number of presentations (regional)

Number of presentations (national)

Number of publications in ethics education

*Doctorate of Philosophy: PhD

*Division I University: DI

\section{Reponses}

PhD: $100 \%$

Yes: $0 \% \quad$ No: $100 \%$

DI: $100 \%$

Zero: $33.33 \% \quad 10+: 66.67 \%$

Zero: $33.33 \% \quad 10+: 66.67 \%$

Zero: $33.33 \% \quad$ 10+: $66.67 \%$

Zero: $33.33 \% \quad 10+: 66.67 \%$ 
Table D2. Percentage Distribution and Mean Scores for First and Second Round Curriculum Components

\begin{tabular}{|c|c|c|c|c|c|c|c|c|c|c|c|c|}
\hline \multirow[t]{2}{*}{ Question } & \multicolumn{2}{|c|}{$\underline{\text { Strong disagree }}$} & \multicolumn{2}{|c|}{ Disagree } & \multicolumn{2}{|c|}{ Neutral } & \multicolumn{2}{|c|}{ Agree } & \multicolumn{2}{|c|}{$\underline{\text { Strongly agree }}$} & \multicolumn{2}{|c|}{ Mean } \\
\hline & R1 & $\mathrm{R} 2$ & $\mathrm{R} 1$ & $\mathrm{R} 2$ & R1 & R2 & R1 & R2 & $\mathrm{R} 1$ & $\mathrm{R} 2$ & $\mathrm{R} 1$ & $\mathrm{R} 2$ \\
\hline $\begin{array}{l}\text { Students should know and understand the NATA } \\
\text { Code of Ethics. }\end{array}$ & $0.00 \%$ & $20.00 \%$ & $0.00 \%$ & $0.00 \%$ & $0.00 \%$ & $0.00 \%$ & $11.11 \%$ & $0.00 \%$ & $88.89 \%$ & $80.00 \%$ & 4.9 & 4.2 \\
\hline $\begin{array}{l}\text { Students should research the professional behavior } \\
\text { standards of the state }\end{array}$ & $0.00 \%$ & $20.00 \%$ & $0.00 \%$ & $0.00 \%$ & $11.11 \%$ & $0.00 \%$ & $0.00 \%$ & $20.00 \%$ & $88.89 \%$ & $60.00 \%$ & 4.8 & 4.2 \\
\hline $\begin{array}{l}\text { Students should know and understand their athletic } \\
\text { training education program's code of ethics }\end{array}$ & $0.00 \%$ & $20.00 \%$ & $0.00 \%$ & $0.00 \%$ & $0.00 \%$ & $0.00 \%$ & $11.11 \%$ & $0.00 \%$ & $88.89 \%$ & $80.00 \%$ & 4.9 & 4.2 \\
\hline $\begin{array}{l}\text { Students should know and understand the } \\
\text { professional responsibilities of an AT }\end{array}$ & $0.00 \%$ & $20.00 \%$ & $0.00 \%$ & $0.00 \%$ & $0.00 \%$ & $0.00 \%$ & $0.00 \%$ & $0.00 \%$ & $100.00 \%$ & $80.00 \%$ & 5 & 4.2 \\
\hline $\begin{array}{l}\text { Students should know and understand the ethical } \\
\text { obligations of the AT profession }\end{array}$ & $0.00 \%$ & $20.00 \%$ & $0.00 \%$ & $0.00 \%$ & $11.11 \%$ & $0.00 \%$ & $0.00 \%$ & $0.00 \%$ & $88.89 \%$ & $80.00 \%$ & 4.8 & 4.2 \\
\hline $\begin{array}{l}\text { Students should know the most relevant medical } \\
\text { ethics history }\end{array}$ & $0.00 \%$ & $20.00 \%$ & $0.00 \%$ & $0.00 \%$ & $0.00 \%$ & $0.00 \%$ & $55.56 \%$ & $40.00 \%$ & $44.44 \%$ & $40.00 \%$ & 4.5 & 3.8 \\
\hline $\begin{array}{l}\text { Students should understand the ethical concept of } \\
\text { patient autonomy }\end{array}$ & $0.00 \%$ & $20.00 \%$ & $0.00 \%$ & $0.00 \%$ & $0.00 \%$ & $0.00 \%$ & $22.22 \%$ & $0.00 \%$ & $77.78 \%$ & $80.00 \%$ & 4.8 & 4.2 \\
\hline $\begin{array}{l}\text { Students should understand the ethical concept of } \\
\text { beneficence }\end{array}$ & $0.00 \%$ & $20.00 \%$ & $0.00 \%$ & $0.00 \%$ & $0.00 \%$ & $0.00 \%$ & $22.22 \%$ & $0.00 \%$ & $77.78 \%$ & $80.00 \%$ & 4.8 & 4.2 \\
\hline $\begin{array}{l}\text { Students should understand the ethical concept of } \\
\text { nonmaleficence }\end{array}$ & $0.00 \%$ & $20.00 \%$ & $0.00 \%$ & $0.00 \%$ & $0.00 \%$ & $0.00 \%$ & $11.11 \%$ & $0.00 \%$ & $88.89 \%$ & $80.00 \%$ & 4.9 & 4.2 \\
\hline $\begin{array}{l}\text { Students should understand the ethical concept of } \\
\text { patient informed consent }\end{array}$ & $0.00 \%$ & $20.00 \%$ & $0.00 \%$ & $0.00 \%$ & $0.00 \%$ & $0.00 \%$ & $11.11 \%$ & $0.00 \%$ & $88.89 \%$ & $80.00 \%$ & 4.9 & 4.2 \\
\hline $\begin{array}{l}\text { Students should be able to clarify between } \\
\text { personal, professional, and organizational values }\end{array}$ & $0.00 \%$ & $20.00 \%$ & $0.00 \%$ & $0.00 \%$ & $0.00 \%$ & $0.00 \%$ & $11.11 \%$ & $0.00 \%$ & $88.89 \%$ & $80.00 \%$ & 4.9 & 4.2 \\
\hline $\begin{array}{l}\text { Students should practice examining and affirming } \\
\text { their own personal and professional moral beliefs }\end{array}$ & $0.00 \%$ & $20.00 \%$ & $0.00 \%$ & $0.00 \%$ & $0.00 \%$ & $0.00 \%$ & $22.22 \%$ & $20.00 \%$ & $77.78 \%$ & $60.00 \%$ & 4.8 & 4 \\
\hline $\begin{array}{l}\text { Students should practice examining the personal } \\
\text { and professional moral beliefs of other people }\end{array}$ & $0.00 \%$ & $0.00 \%$ & $0.00 \%$ & $0.00 \%$ & $11.11 \%$ & $40.00 \%$ & $22.22 \%$ & $20.00 \%$ & $66.67 \%$ & $40.00 \%$ & 4.6 & 4 \\
\hline $\begin{array}{l}\text { Students should understand and identify barriers to } \\
\text { ethical practice }\end{array}$ & $0.00 \%$ & $20.00 \%$ & $0.00 \%$ & $0.00 \%$ & $0.00 \%$ & $0.00 \%$ & $11.11 \%$ & $0.00 \%$ & $88.89 \%$ & $80.00 \%$ & 4.9 & 4.2 \\
\hline $\begin{array}{l}\text { Students should be able to recognize situations } \\
\text { involving unethical decision-making }\end{array}$ & $0.00 \%$ & $0.00 \%$ & $0.00 \%$ & $0.00 \%$ & $0.00 \%$ & $0.00 \%$ & $11.11 \%$ & $20.00 \%$ & $88.89 \%$ & $80.00 \%$ & 4.9 & 4.8 \\
\hline $\begin{array}{l}\text { Students should practice effective communication } \\
\text { skills necessary to report ethical concerns }\end{array}$ & $0.00 \%$ & $20.00 \%$ & $0.00 \%$ & $0.00 \%$ & $0.00 \%$ & $0.00 \%$ & $0.00 \%$ & $0.00 \%$ & $100.00 \%$ & $80.00 \%$ & 5 & 4.2 \\
\hline $\begin{array}{l}\text { Students should practice communicating with other } \\
\text { fellow healthcare providers to resolve ethical } \\
\text { situations }\end{array}$ & $0.00 \%$ & $20.00 \%$ & $0.00 \%$ & $0.00 \%$ & $0.00 \%$ & $0.00 \%$ & $11.11 \%$ & $0.00 \%$ & $88.89 \%$ & $80.00 \%$ & 4.9 & 4.2 \\
\hline $\begin{array}{l}\text { Students should utilize ethical decision-making } \\
\text { frameworks when formulating a plan of action }\end{array}$ & $0.00 \%$ & $0.00 \%$ & $0.00 \%$ & $0.00 \%$ & $22.22 \%$ & $60.00 \%$ & $11.11 \%$ & $20.00 \%$ & $66.67 \%$ & $20.00 \%$ & 4.5 & 3.6 \\
\hline $\begin{array}{l}\text { Students should know and understand the } \\
\text { professional and legal consequences of poor ethical } \\
\text { decisions }\end{array}$ & $0.00 \%$ & $20.00 \%$ & $0.00 \%$ & $0.00 \%$ & $0.00 \%$ & $0.00 \%$ & $11.11 \%$ & $0.00 \%$ & $88.89 \%$ & $80.00 \%$ & 4.9 & 4.2 \\
\hline
\end{tabular}




\section{Table D3. Percentage Distribution and Mean Scores for First and Second Round Athletic Trainer Misconduct}

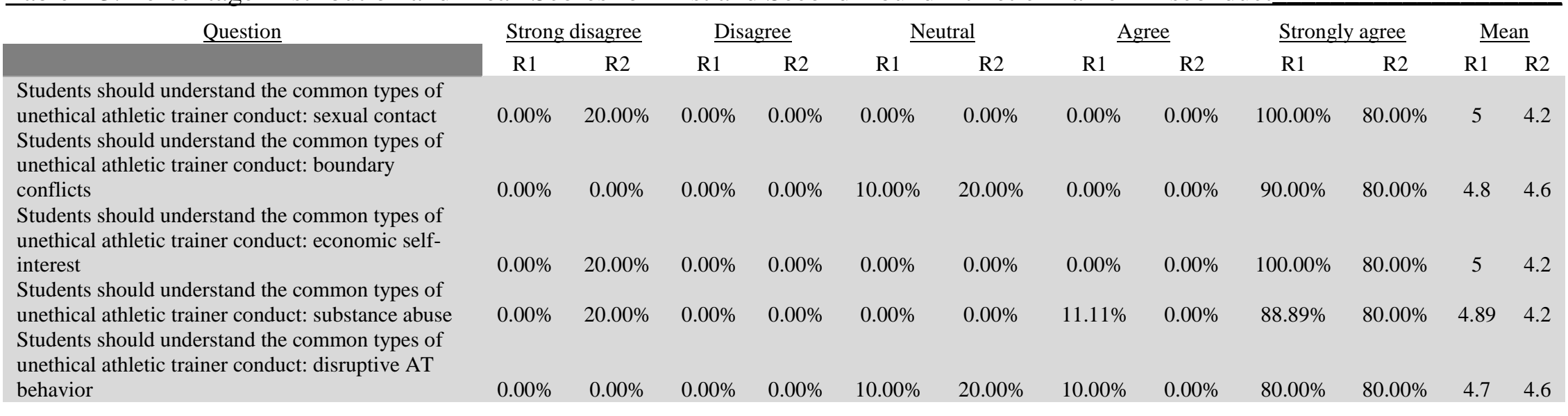

Key: R= Round; highlight= included in guidelines

Table D4. Percentage Distribution and Mean Scores for First and Second Round Ethics Competencies

\begin{tabular}{|c|c|c|c|c|c|c|c|c|c|c|c|c|}
\hline \multirow[t]{2}{*}{ Question } & \multicolumn{2}{|c|}{$\underline{\text { Strong disagree }}$} & \multicolumn{2}{|c|}{$\underline{\text { Disagree }}$} & \multicolumn{2}{|c|}{$\underline{\text { Neutral }}$} & \multicolumn{2}{|c|}{$\underline{\text { Agree }}$} & \multicolumn{2}{|c|}{ Strongly agree } & \multicolumn{2}{|c|}{$\underline{\text { Mean }}$} \\
\hline & $\mathrm{R} 1$ & $\mathrm{R} 2$ & $\mathrm{R} 1$ & $\mathrm{R} 2$ & $\mathrm{R} 1$ & $\mathrm{R} 2$ & $\mathrm{R} 1$ & $\mathrm{R} 2$ & $\mathrm{R} 1$ & $\mathrm{R} 2$ & $\mathrm{R} 1$ & $\mathrm{R} 2$ \\
\hline $\begin{array}{l}\text { Students should demonstrate ethical standards } \\
\text { that correspond with NATA Code of Ethics }\end{array}$ & $0.00 \%$ & $0.00 \%$ & $0.00 \%$ & $0.00 \%$ & $10.00 \%$ & $0.00 \%$ & $10.00 \%$ & $0.00 \%$ & $80.00 \%$ & $100.00 \%$ & 4.7 & 5 \\
\hline $\begin{array}{l}\text { Students should demonstrate the ability to } \\
\text { document a patient's informed consent }\end{array}$ & $0.00 \%$ & $0.00 \%$ & $0.00 \%$ & $0.00 \%$ & $0.00 \%$ & $0.00 \%$ & $10.00 \%$ & $0.00 \%$ & $90.00 \%$ & $100.00 \%$ & 4.9 & 5 \\
\hline $\begin{array}{l}\text { Students should demonstrate the ability to act } \\
\text { appropriately if a patient is incompetent }\end{array}$ & $10.00 \%$ & $0.00 \%$ & $0.00 \%$ & $0.00 \%$ & $10.00 \%$ & $25.00 \%$ & $10.00 \%$ & $0.00 \%$ & $70.00 \%$ & $75.00 \%$ & 4.3 & 4.5 \\
\hline $\begin{array}{l}\text { Students should demonstrate the ability to act } \\
\text { appropriately if a patient refuses treatment }\end{array}$ & $0.00 \%$ & $0.00 \%$ & $0.00 \%$ & $0.00 \%$ & $0.00 \%$ & $0.00 \%$ & $20.00 \%$ & $0.00 \%$ & $80.00 \%$ & $100.00 \%$ & 4.8 & 5 \\
\hline $\begin{array}{l}\text { Students should demonstrate the ability to } \\
\text { document patient refusal of treatment }\end{array}$ & $0.00 \%$ & $0.00 \%$ & $0.00 \%$ & $0.00 \%$ & $0.00 \%$ & $0.00 \%$ & $20.00 \%$ & $0.00 \%$ & $80.00 \%$ & $100.00 \%$ & 4.8 & 5 \\
\hline $\begin{array}{l}\text { Students should demonstrate the ability to } \\
\text { decide when it is ethically justified to } \\
\text { withhold information }\end{array}$ & $20.00 \%$ & $25.00 \%$ & $0.00 \%$ & $0.00 \%$ & $0.00 \%$ & $25.00 \%$ & $20.00 \%$ & $0.00 \%$ & $60.00 \%$ & $50.00 \%$ & 4 & 3.5 \\
\hline $\begin{array}{l}\text { Students should demonstrate the ability to } \\
\text { decide when it is ethically justified to breach } \\
\text { confidentiality }\end{array}$ & $10.00 \%$ & $0.00 \%$ & $0.00 \%$ & $0.00 \%$ & $10.00 \%$ & $25.00 \%$ & $20.00 \%$ & $0.00 \%$ & $60.00 \%$ & $75.00 \%$ & 4.2 & 4.5 \\
\hline
\end{tabular}




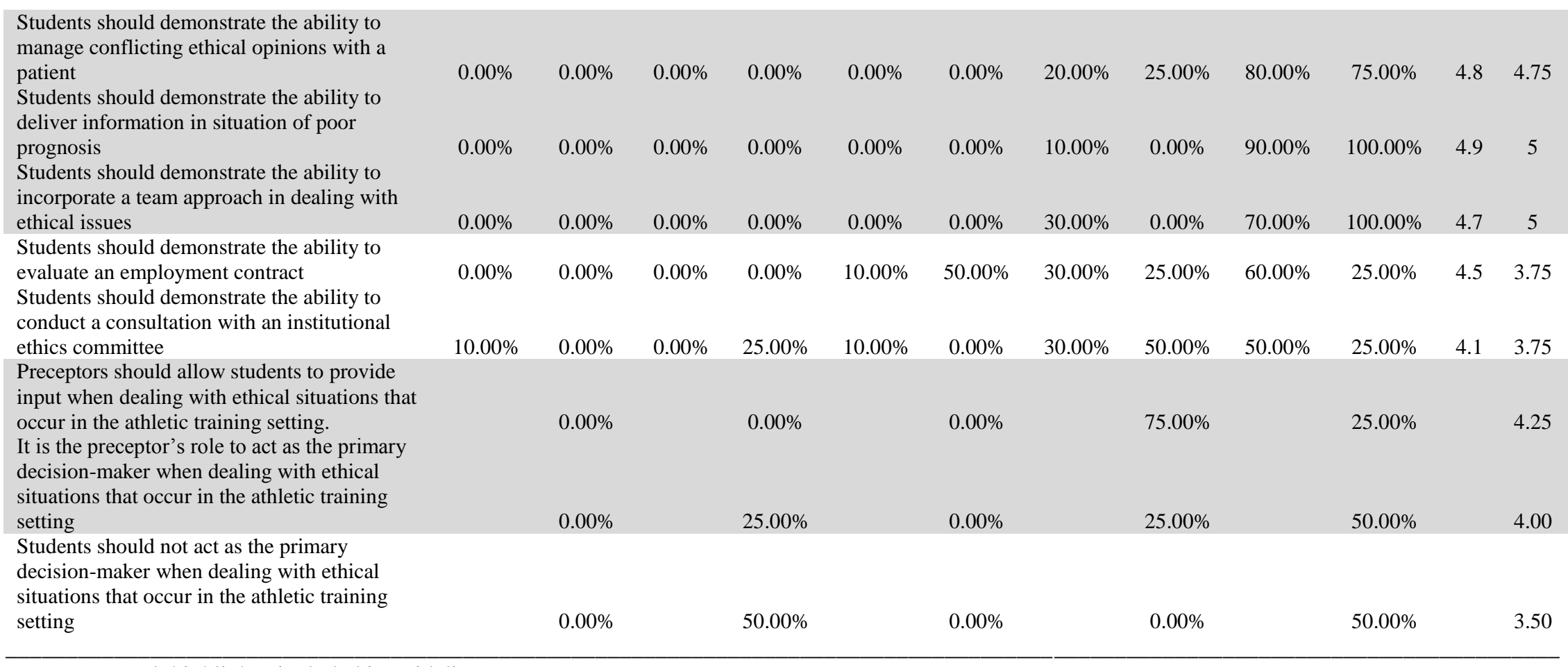

Key: $\mathrm{R}=$ Round; highlight= included in guidelines

Table D5. Percentage Distribution and Mean Scores for First and Second Round Educational Methods

\begin{tabular}{|c|c|c|c|c|c|c|c|c|c|c|c|c|}
\hline \multirow[t]{2}{*}{ Question } & \multicolumn{2}{|c|}{$\underline{\text { Strong disagree }}$} & \multicolumn{2}{|c|}{$\underline{\text { Disagree }}$} & \multicolumn{2}{|c|}{$\underline{\text { Neutral }}$} & \multicolumn{2}{|c|}{$\underline{\text { Agree }}$} & \multicolumn{2}{|c|}{$\underline{\text { Strongly agree }}$} & \multicolumn{2}{|c|}{$\underline{\text { Mean }}$} \\
\hline & $\mathrm{R} 1$ & $\mathrm{R} 2$ & $\mathrm{R} 1$ & $\mathrm{R} 2$ & $\mathrm{R} 1$ & $\mathrm{R} 2$ & $\mathrm{R} 1$ & $\mathrm{R} 2$ & $\mathrm{R} 1$ & $\mathrm{R} 2$ & $\mathrm{R} 1$ & $\mathrm{R} 2$ \\
\hline $\begin{array}{l}\text { Ethical decision-making is most effectively } \\
\text { taught through role-play. }\end{array}$ & $0.00 \%$ & $0.00 \%$ & $10.00 \%$ & $0.00 \%$ & $40.00 \%$ & $50.00 \%$ & $40.00 \%$ & $50.00 \%$ & $10.00 \%$ & $0.00 \%$ & 3.5 & 3.5 \\
\hline $\begin{array}{l}\text { Ethical decision-making is most effectively } \\
\text { taught through scenario-based exercises. }\end{array}$ & $0.00 \%$ & $0.00 \%$ & $0.00 \%$ & $0.00 \%$ & $10.00 \%$ & $25.00 \%$ & $80.00 \%$ & $75.00 \%$ & $10.00 \%$ & $0.00 \%$ & 4 & 3.75 \\
\hline $\begin{array}{l}\text { Ethical decision-making is most efrectivery } \\
\text { taught through reflective journaling. }\end{array}$ & $0.00 \%$ & $0.00 \%$ & $30.00 \%$ & $50.00 \%$ & $10.00 \%$ & $0.00 \%$ & $60.00 \%$ & $50.00 \%$ & $0.00 \%$ & $0.00 \%$ & 3.3 & 3 \\
\hline $\begin{array}{l}\text { Ethical decision-making is most effectively } \\
\text { taught through mentoring. }\end{array}$ & $0.00 \%$ & $0.00 \%$ & $0.00 \%$ & $0.00 \%$ & $40.00 \%$ & $50.00 \%$ & $40.00 \%$ & $50.00 \%$ & $20.00 \%$ & $0.00 \%$ & 3.8 & 3.5 \\
\hline others. & $0.00 \%$ & $0.00 \%$ & $10.00 \%$ & $25.00 \%$ & $30.00 \%$ & $50.00 \%$ & $40.00 \%$ & $25.00 \%$ & $20.00 \%$ & $0.00 \%$ & 3.7 & 3 \\
\hline
\end{tabular}


Ethical decision-making is most effectively taught through clinical experience.
Ethical decision-making is most effectively

Ethical decision-making is most effectively

Ethical decision-making is most effectively

taught through small group activities.

$\begin{array}{rrrrrrrrrrrrr}20.00 \% & 25.00 \% & 20.00 \% & 0.00 \% & 50.00 \% & 75.00 \% & 10.00 \% & 0.00 \% & 0.00 \% & 0.00 \% & 2.5 & 2.5 \\ 0.00 \% & 0.00 \% & 0.00 \% & 0.00 \% & 40.00 \% & 50.00 \% & 50.00 \% & 50.00 \% & 10.00 \% & 0.00 \% & 3.7 & 3.5 \\ 0.00 \% & 0.00 \% & 0.00 \% & 0.00 \% & 30.00 \% & 25.00 \% & 50.00 \% & 50.00 \% & 20.00 \% & 25.00 \% & 3.9 & 4 \\ 0.00 \% & 0.00 \% & 30.00 \% & 50.00 \% & 30.00 \% & 25.00 \% & 40.00 \% & 25.00 \% & 0.00 \% & 0.00 \% & 3.1 & 2.75 \\ 0.00 \% & 0.00 \% & 20.00 \% & 25.00 \% & 40.00 \% & 50.00 \% & 40.00 \% & 25.00 \% & 0.00 \% & 0.00 \% & 3.2 & 3 \\ 0.00 \% & 0.00 \% & 40.00 \% & 50.00 \% & 40.00 \% & 25.00 \% & 20.00 \% & 25.00 \% & 0.00 \% & 0.00 \% & 2.8 & 2.75\end{array}$

Ethical decision-making is most effectively

taught through case study discussion in the

classroom.

Ethical decision-making is most effectively

taught through classroom presentations.

Ethical decision-making is most effectively

taught through writing assignments.

lines

Key: R= Round; highlight= included in guidelines

Table D6. Percentage Distribution and Mean Scores for First and Second Round Presentation of Curriculum

\begin{tabular}{|c|c|c|c|c|c|c|c|c|c|c|c|c|}
\hline \multirow[t]{2}{*}{ Question } & \multicolumn{2}{|c|}{$\underline{\text { Strong disagree }}$} & \multicolumn{2}{|c|}{ Disagree } & \multicolumn{2}{|c|}{$\underline{\text { Neutral }}$} & \multicolumn{2}{|c|}{ Agree } & \multicolumn{2}{|c|}{$\underline{\text { Strongly agree }}$} & \multicolumn{2}{|c|}{ Mean } \\
\hline & $\mathrm{R} 1$ & $\mathrm{R} 2$ & $\mathrm{R} 1$ & $\mathrm{R} 2$ & $\mathrm{R} 1$ & $\mathrm{R} 2$ & $\mathrm{R} 1$ & $\mathrm{R} 2$ & $\mathrm{R} 1$ & $\mathrm{R} 2$ & $\mathrm{R} 1$ & $\mathrm{R} 2$ \\
\hline $\begin{array}{l}\text { Ethics training is best delivered in a stand- } \\
\text { alone course. }\end{array}$ & $0.00 \%$ & $0.00 \%$ & $0.00 \%$ & $0.00 \%$ & $40.00 \%$ & $25.00 \%$ & $40.00 \%$ & $50.00 \%$ & $20.00 \%$ & $25.00 \%$ & 3.8 & 4 \\
\hline $\begin{array}{l}\text { Ethics training is best delivered as an } \\
\text { objective within a larger course. }\end{array}$ & $0.00 \%$ & $0.00 \%$ & $20.00 \%$ & $25.00 \%$ & $20.00 \%$ & $50.00 \%$ & $50.00 \%$ & $25.00 \%$ & $10.00 \%$ & $0.00 \%$ & 3.5 & 3 \\
\hline $\begin{array}{l}\text { Ethics training is best delivered within an } \\
\text { online module. }\end{array}$ & $20.00 \%$ & $25.00 \%$ & $30.00 \%$ & $50.00 \%$ & $40.00 \%$ & $0.00 \%$ & $10.00 \%$ & $25.00 \%$ & $0.00 \%$ & $0.00 \%$ & 2.4 & 2.25 \\
\hline $\begin{array}{l}\text { Ethics training is best delivered within a } \\
\text { professional conference. }\end{array}$ & $20.00 \%$ & $25.00 \%$ & $30.00 \%$ & $50.00 \%$ & $40.00 \%$ & $0.00 \%$ & $10.00 \%$ & $25.00 \%$ & $0.00 \%$ & $0.00 \%$ & 2.4 & 2.25 \\
\hline $\begin{array}{l}\text { Ethics training is best delivered within journal } \\
\text { publications. }\end{array}$ & $10.00 \%$ & $0.00 \%$ & $20.00 \%$ & $75.00 \%$ & $60.00 \%$ & $0.00 \%$ & $10.00 \%$ & $25.00 \%$ & $0.00 \%$ & $0.00 \%$ & 2.7 & 2.5 \\
\hline
\end{tabular}

Key: R= Round; highlight= included in guidelines 
Table D7. Percentage Distribution and Mean Scores for First and Second Round Program Requirements

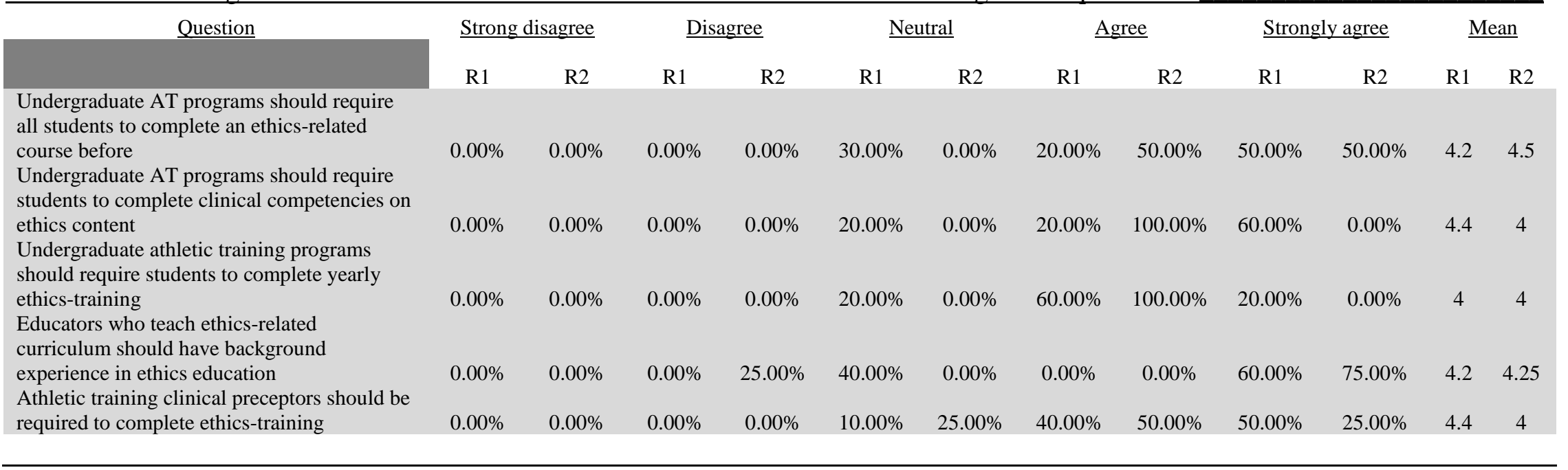

Key: R= Round; highlight= included in guidelines

Table D8. Final Ethics Education Guidelines

Question
Students should know and understand the NATA
Code of Ethics.
Students should research the professional
behavior standards of the state
Students should know and understand their
athletic training education program's code of
ethics
Students should know and understand the
professional responsibilities of an AT
Students should know and understand the ethical
obligations of the AT profession

Students should understand the ethical concept of patient autonomy

Students should understand the ethical concept of beneficence

\begin{tabular}{|c|c|c|c|c|c|c|c|c|c|c|c|}
\hline \multicolumn{2}{|c|}{$\underline{\text { Strong disagree }}$} & \multicolumn{2}{|c|}{ Disagree } & \multicolumn{2}{|c|}{ Neutral } & \multicolumn{2}{|c|}{ Agree } & \multicolumn{2}{|c|}{$\underline{\text { Strongly agree }}$} & \multicolumn{2}{|c|}{$\underline{\text { Mean }}$} \\
\hline $\mathrm{R} 1$ & $\mathrm{R} 2$ & $\mathrm{R} 1$ & $\mathrm{R} 2$ & $\mathrm{R} 1$ & $\mathrm{R} 2$ & $\mathrm{R} 1$ & $\mathrm{R} 2$ & $\mathrm{R} 1$ & $\mathrm{R} 2$ & $\mathrm{R} 1$ & $\mathrm{R} 2$ \\
\hline $0.00 \%$ & $20.00 \%$ & $0.00 \%$ & $0.00 \%$ & $0.00 \%$ & $0.00 \%$ & $11.11 \%$ & $0.00 \%$ & $88.89 \%$ & $80.00 \%$ & 4.9 & 4.2 \\
\hline $0.00 \%$ & $20.00 \%$ & $0.00 \%$ & $0.00 \%$ & $11.11 \%$ & $0.00 \%$ & $0.00 \%$ & $20.00 \%$ & $88.89 \%$ & $60.00 \%$ & 4.8 & 4.2 \\
\hline $0.00 \%$ & $20.00 \%$ & $0.00 \%$ & $0.00 \%$ & $0.00 \%$ & $0.00 \%$ & $11.11 \%$ & $0.00 \%$ & $88.89 \%$ & $80.00 \%$ & 4.9 & 4.2 \\
\hline $0.00 \%$ & $20.00 \%$ & $0.00 \%$ & $0.00 \%$ & $0.00 \%$ & $0.00 \%$ & $0.00 \%$ & $0.00 \%$ & $100.00 \%$ & $80.00 \%$ & 5 & 4.2 \\
\hline $0.00 \%$ & $20.00 \%$ & $0.00 \%$ & $0.00 \%$ & $11.11 \%$ & $0.00 \%$ & $0.00 \%$ & $0.00 \%$ & $88.89 \%$ & $80.00 \%$ & 4.8 & 4.2 \\
\hline
\end{tabular}

$\begin{array}{llllllllllll}0.00 \% & 20.00 \% & 0.00 \% & 0.00 \% & 0.00 \% & 0.00 \% & 22.22 \% & 0.00 \% & 77.78 \% & 80.00 \% & 4.8 & 4.2 \\ 0.00 \% & 20.00 \% & 0.00 \% & 0.00 \% & 0.00 \% & 0.00 \% & 22.22 \% & 0.00 \% & 77.78 \% & 80.00 \% & 4.8 & 4.2\end{array}$


Students should understand the ethical concept of nonmaleficence

Students should understand the ethical concept of patient informed consent

Students should be able to clarify between

personal, professional, and organizational values

Students should practice examining and affirming

their own personal and professional moral beliefs

Students should practice examining the personal

and professional moral beliefs of other people

Students should understand and identify barriers

to ethical practice

Students should understand and identify barriers

to ethical practice

Students should be able to recognize situations

involving unethical decision-making

Students should practice effective communication

skills necessary to report ethical concerns

Students should practice communicating with

other fellow healthcare providers to resolve

ethical situations

Students should know and understand the

professional and legal consequences of poor

ethical decisions

Students should understand the common types of

unethical athletic trainer conduct: sexual contact

Students should understand the common types of

unethical athletic trainer conduct: boundary

conflicts

Students should understand the common types of

unethical athletic trainer conduct: economic self-

interest

Students should understand the common types of

unethical athletic trainer conduct: substance abuse

Students should understand the common types of

unethical athletic trainer conduct: disruptive AT

behavior

Students should demonstrate ethical standards

that correspond with NATA Code of Ethics

Students should demonstrate the ability to

document a patient's informed consent

Students should demonstrate the ability to act

appropriately if a patient is incompetent

Students should demonstrate the ability to act

appropriately if a patient refuses treatment

\begin{tabular}{|c|c|c|c|c|c|c|c|c|c|c|}
\hline $0.00 \%$ & $20.00 \%$ & $0.00 \%$ & $0.00 \%$ & $0.00 \%$ & $0.00 \%$ & $11.11 \%$ & $0.00 \%$ & $88.89 \%$ & $80.00 \%$ & 4.9 \\
\hline $0.00 \%$ & $20.00 \%$ & $0.00 \%$ & $0.00 \%$ & $0.00 \%$ & $0.00 \%$ & $11.11 \%$ & $0.00 \%$ & $88.89 \%$ & $80.00 \%$ & 4.9 \\
\hline $0.00 \%$ & $20.00 \%$ & $0.00 \%$ & $0.00 \%$ & $0.00 \%$ & $0.00 \%$ & $11.11 \%$ & $0.00 \%$ & $88.89 \%$ & $80.00 \%$ & 4.9 \\
\hline $0.00 \%$ & $20.00 \%$ & $0.00 \%$ & $0.00 \%$ & $0.00 \%$ & $0.00 \%$ & $22.22 \%$ & $20.00 \%$ & $77.78 \%$ & $60.00 \%$ & 4.8 \\
\hline $0.00 \%$ & $0.00 \%$ & $0.00 \%$ & $0.00 \%$ & $11.11 \%$ & $40.00 \%$ & $22.22 \%$ & $20.00 \%$ & $66.67 \%$ & $40.00 \%$ & 4.6 \\
\hline $0.00 \%$ & $20.00 \%$ & $0.00 \%$ & $0.00 \%$ & $0.00 \%$ & $0.00 \%$ & $11.11 \%$ & $0.00 \%$ & $88.89 \%$ & $80.00 \%$ & 4.9 \\
\hline $0.00 \%$ & $20.00 \%$ & $0.00 \%$ & $0.00 \%$ & $0.00 \%$ & $0.00 \%$ & $11.11 \%$ & $0.00 \%$ & $88.89 \%$ & $80.00 \%$ & 4.9 \\
\hline $0.00 \%$ & $0.00 \%$ & $0.00 \%$ & $0.00 \%$ & $0.00 \%$ & $0.00 \%$ & $11.11 \%$ & $20.00 \%$ & $88.89 \%$ & $80.00 \%$ & 4.9 \\
\hline $0.00 \%$ & $20.00 \%$ & $0.00 \%$ & $0.00 \%$ & $0.00 \%$ & $0.00 \%$ & $0.00 \%$ & $0.00 \%$ & $100.00 \%$ & $80.00 \%$ & 5 \\
\hline $0.00 \%$ & $20.00 \%$ & $0.00 \%$ & $0.00 \%$ & $0.00 \%$ & $0.00 \%$ & $11.11 \%$ & $0.00 \%$ & $88.89 \%$ & $80.00 \%$ & 4.9 \\
\hline $0.00 \%$ & $20.00 \%$ & $0.00 \%$ & $0.00 \%$ & $0.00 \%$ & $0.00 \%$ & $11.11 \%$ & $0.00 \%$ & $88.89 \%$ & $80.00 \%$ & 4.9 \\
\hline $0.00 \%$ & $20.00 \%$ & $0.00 \%$ & $0.00 \%$ & $0.00 \%$ & $0.00 \%$ & $0.00 \%$ & $0.00 \%$ & $100.00 \%$ & $80.00 \%$ & 5 \\
\hline $0.00 \%$ & $0.00 \%$ & $0.00 \%$ & $0.00 \%$ & $10.00 \%$ & $20.00 \%$ & $0.00 \%$ & $0.00 \%$ & $90.00 \%$ & $80.00 \%$ & 4.8 \\
\hline $0.00 \%$ & $20.00 \%$ & $0.00 \%$ & $0.00 \%$ & $0.00 \%$ & $0.00 \%$ & $0.00 \%$ & $0.00 \%$ & $100.00 \%$ & $80.00 \%$ & 5 \\
\hline $0.00 \%$ & $20.00 \%$ & $0.00 \%$ & $0.00 \%$ & $0.00 \%$ & $0.00 \%$ & $11.11 \%$ & $0.00 \%$ & $88.89 \%$ & $80.00 \%$ & 4.89 \\
\hline $0.00 \%$ & $0.00 \%$ & $0.00 \%$ & $0.00 \%$ & $10.00 \%$ & $20.00 \%$ & $10.00 \%$ & $0.00 \%$ & $80.00 \%$ & $80.00 \%$ & 4.7 \\
\hline $0.00 \%$ & $0.00 \%$ & $0.00 \%$ & $0.00 \%$ & $10.00 \%$ & $0.00 \%$ & $10.00 \%$ & $0.00 \%$ & $80.00 \%$ & $100.00 \%$ & 4.7 \\
\hline $0.00 \%$ & $0.00 \%$ & $0.00 \%$ & $0.00 \%$ & $0.00 \%$ & $0.00 \%$ & $10.00 \%$ & $0.00 \%$ & $90.00 \%$ & $100.00 \%$ & 4.9 \\
\hline $10.00 \%$ & $0.00 \%$ & $0.00 \%$ & $0.00 \%$ & $10.00 \%$ & $25.00 \%$ & $10.00 \%$ & $0.00 \%$ & $70.00 \%$ & $75.00 \%$ & 4.3 \\
\hline $0.00 \%$ & $0.00 \%$ & $0.00 \%$ & $0.00 \%$ & $0.00 \%$ & $0.00 \%$ & $20.00 \%$ & $0.00 \%$ & $80.00 \%$ & $100.00 \%$ & 4.8 \\
\hline
\end{tabular}


Students should demonstrate the ability to document patient refusal of treatment

Students should demonstrate the ability to decide

when it is ethically justified to breach

confidentiality

Students should demonstrate the ability to manage

conflicting ethical opinions with a patient

Students should demonstrate the ability to deliver

information in situation of poor prognosis

Students should demonstrate the ability to

incorporate a team approach in dealing with

ethical issues

Preceptors should allow students to provide input when dealing with ethical situations that occur in

the athletic training setting.

It is the preceptor's role to act as the primary

decision-maker when dealing with ethical

situations that occur in the athletic training setting

Ethical decision-making is most effectively taught

through case study discussion in the classroom.

Ethics training is best delivered in a stand-alone

course.

Undergraduate AT programs should require all

students to complete an ethics-related course

before

Undergraduate AT programs should require

students to complete clinical competencies on

ethics content

Undergraduate athletic training programs should

require students to complete yearly ethics-training

Educators who teach ethics-related curriculum

should have background experience in ethics

education

Athletic training clinical preceptors should be

required to complete ethics-training

\begin{tabular}{|c|c|c|c|c|c|c|c|c|c|c|c|}
\hline $0.00 \%$ & $0.00 \%$ & $0.00 \%$ & $0.00 \%$ & $0.00 \%$ & $0.00 \%$ & $20.00 \%$ & $0.00 \%$ & $80.00 \%$ & $100.00 \%$ & 4.8 & 5 \\
\hline $10.00 \%$ & $0.00 \%$ & $0.00 \%$ & $0.00 \%$ & $10.00 \%$ & $25.00 \%$ & $20.00 \%$ & $0.00 \%$ & $60.00 \%$ & $75.00 \%$ & 4.2 & 4.5 \\
\hline $0.00 \%$ & $0.00 \%$ & $0.00 \%$ & $0.00 \%$ & $0.00 \%$ & $0.00 \%$ & $20.00 \%$ & $25.00 \%$ & $80.00 \%$ & $75.00 \%$ & 4.8 & 4.7 \\
\hline $0.00 \%$ & $0.00 \%$ & $0.00 \%$ & $0.00 \%$ & $0.00 \%$ & $0.00 \%$ & $10.00 \%$ & $0.00 \%$ & $90.00 \%$ & $100.00 \%$ & 4.9 & 5 \\
\hline $0.00 \%$ & $0.00 \%$ & $0.00 \%$ & $0.00 \%$ & $0.00 \%$ & $0.00 \%$ & $30.00 \%$ & $0.00 \%$ & $70.00 \%$ & $100.00 \%$ & 4.7 & 5 \\
\hline & $0.00 \%$ & & $0.00 \%$ & & $0.00 \%$ & & $75.00 \%$ & & $25.00 \%$ & & 4.2 \\
\hline & $0.00 \%$ & & $25.00 \%$ & & $0.00 \%$ & & $25.00 \%$ & & $50.00 \%$ & & 4.0 \\
\hline $0.00 \%$ & $0.00 \%$ & $0.00 \%$ & $0.00 \%$ & $30.00 \%$ & $25.00 \%$ & $50.00 \%$ & $50.00 \%$ & $20.00 \%$ & $25.00 \%$ & 3.9 & 4 \\
\hline $0.00 \%$ & $0.00 \%$ & $0.00 \%$ & $0.00 \%$ & $40.00 \%$ & $25.00 \%$ & $40.00 \%$ & $50.00 \%$ & $20.00 \%$ & $25.00 \%$ & 3.8 & 4 \\
\hline $0.00 \%$ & $0.00 \%$ & $0.00 \%$ & $0.00 \%$ & $30.00 \%$ & $0.00 \%$ & $20.00 \%$ & $50.00 \%$ & $50.00 \%$ & $50.00 \%$ & 4.2 & 4.5 \\
\hline $0.00 \%$ & $0.00 \%$ & $0.00 \%$ & $0.00 \%$ & $20.00 \%$ & $0.00 \%$ & $20.00 \%$ & $100.00 \%$ & $60.00 \%$ & $0.00 \%$ & 4.4 & 4 \\
\hline $0.00 \%$ & $0.00 \%$ & $0.00 \%$ & $0.00 \%$ & $20.00 \%$ & $0.00 \%$ & $60.00 \%$ & $100.00 \%$ & $20.00 \%$ & $0.00 \%$ & 4 & 4 \\
\hline $0.00 \%$ & $0.00 \%$ & $0.00 \%$ & $25.00 \%$ & $40.00 \%$ & $0.00 \%$ & $0.00 \%$ & $0.00 \%$ & $60.00 \%$ & $75.00 \%$ & 4.2 & 4.25 \\
\hline $0.00 \%$ & $0.00 \%$ & $0.00 \%$ & $0.00 \%$ & $10.00 \%$ & $25.00 \%$ & $40.00 \%$ & $50.00 \%$ & $50.00 \%$ & $25.00 \%$ & 4.4 & 4 \\
\hline
\end{tabular}


Figure D1. Example Phase Placement Timeline of Final Ethics Guidelines

\begin{tabular}{|c|c|c|c|c|c|c|c|c|}
\hline & Phase 1 & Phase 2 & Phase 3 & Phase 4 & Phase 5 & Phase 6 & Phase 7 & Phase 8 \\
\hline Discuss NATA Code of Ethics & & & & $\Rightarrow$ & & & & \\
\hline Discuss AT program code of ethics & & & & $\rightarrow$ & & & & \\
\hline $\begin{array}{l}\text { Professional behavior standards of practicing } \\
\text { state }\end{array}$ & & & & & & & & \\
\hline Professional responsibilities of ATs & & & & & & & & \\
\hline Discuss ethical obligations of ATs & & & & $\rightarrow$ & & & & \\
\hline Discuss ethical concept of patient autonomy & & $\Rightarrow$ & & & & & & \\
\hline Discuss ethical concept of beneficence & & $\rightarrow$ & & & & & & \\
\hline Discuss ethical concept of nonmaleficence & & $\rightarrow$ & & & & & & \\
\hline $\begin{array}{l}\text { Discuss ethical concept of patient informed } \\
\text { consent }\end{array}$ & & & & & & & & \\
\hline $\begin{array}{l}\text { Students practice clarifying between personal, } \\
\text { professional, organizational moral values }\end{array}$ & & & & & & & & \\
\hline $\begin{array}{l}\text { Students examine their own personal and } \\
\text { professional morals }\end{array}$ & & & & & & & & \\
\hline $\begin{array}{l}\text { Students examine personal and professional } \\
\text { morals of others }\end{array}$ & & & & & & & & \\
\hline Identify barriers to ethical practice & & $\rightarrow$ & & & & & & \\
\hline $\begin{array}{l}\text { Identify situations involving unethical decision- } \\
\text { making }\end{array}$ & & & & & & $\Rightarrow$ & & \\
\hline $\begin{array}{l}\text { Practicing effective communication skills } \\
\text { necessary to report ethical concerns }\end{array}$ & & & & & & & & \\
\hline $\begin{array}{l}\text { Practicing effective communication skills to } \\
\text { resolve ethical situations }\end{array}$ & & & & & & & & \\
\hline $\begin{array}{l}\text { Discuss professional and legal consequences of } \\
\text { poor ethical decisions }\end{array}$ & & & & & & & & \\
\hline
\end{tabular}




\begin{tabular}{|c|c|c|c|c|c|c|c|c|}
\hline \multirow{2}{*}{$\begin{array}{l} \\
\text { Identify common types of unethical athletic trainer } \\
\text { conduct: romantic relationships and sexual contact } \\
\text { with patients }\end{array}$} & Phase 1 & \begin{tabular}{|l} 
Phase 2 \\
\end{tabular} & Phase 3 & Phase 4 & \begin{tabular}{|l} 
Phase 5 \\
\end{tabular} & Phase 6 & Phase 7 & \begin{tabular}{|l} 
Phase 8 \\
\end{tabular} \\
\hline & & & & & & $\rightarrow$ & & \\
\hline \multicolumn{9}{|l|}{$\begin{array}{l}\text { Identify common types of unethical athletic trainer } \\
\text { conduct: boundary conflicts }\end{array}$} \\
\hline \multicolumn{9}{|l|}{$\begin{array}{l}\text { Identify common types of unethical athletic trainer } \\
\text { conduct: economic self-interest }\end{array}$} \\
\hline \multicolumn{9}{|l|}{$\begin{array}{l}\text { Identify common types of unethical athletic trainer } \\
\text { conduct: substance abuse }\end{array}$} \\
\hline \multicolumn{9}{|l|}{$\begin{array}{l}\text { Identify common types of unethical athletic trainer } \\
\text { conduct: disruptive AT behavior }\end{array}$} \\
\hline \multicolumn{9}{|l|}{$\begin{array}{l}\text { Students demonstrate documenting patient informed } \\
\text { consent }\end{array}$} \\
\hline \multicolumn{9}{|l|}{$\begin{array}{l}\text { Students demonstrate proper management of a } \\
\text { patient who is incompetent to make medical } \\
\text { decisions }\end{array}$} \\
\hline \multicolumn{9}{|l|}{$\begin{array}{l}\text { Students demonstrate proper management of a } \\
\text { patient who refuses medical treatment/advice }\end{array}$} \\
\hline \multicolumn{9}{|l|}{$\begin{array}{l}\text { Student demonstrate documenting of patient refusal } \\
\text { of treatment }\end{array}$} \\
\hline \multicolumn{9}{|l|}{$\begin{array}{l}\text { Students demonstrate decision-making process to } \\
\text { ethically justify breaching patient confidentiality }\end{array}$} \\
\hline \multicolumn{9}{|l|}{$\begin{array}{l}\text { Students demonstrate proper management of } \\
\text { conflicting ethical opinions with patient }\end{array}$} \\
\hline \multicolumn{9}{|l|}{$\begin{array}{l}\text { Students demonstrate the ability to deliver } \\
\text { information in the event of poor prognosis }\end{array}$} \\
\hline $\begin{array}{l}\text { Students demonstrate ability to incorporate team } \\
\text { approach in dealing with ethical issues }\end{array}$ & & & & & & & & $\longrightarrow$ \\
\hline
\end{tabular}




\section{APPENDIX E}

\section{RECOMMENDATIONS FOR FUTURE RESEARCH}

1. A recommendation for future research would be to recruit more experts in the field of medical ethics. This could be accomplished by utilizing an online database to reach more people.

2. Another recommendation would be to take this information to the next step of creating a specific ethics course curriculum for athletic training programs. This could be accomplished by investigating current ethics curriculums utilized by medical, nursing, and allied health programs.

3. In order to recruit more subjects, funding for participation incentives may be necessary (i.e. drawing for gift card).

4. In addition, the Board of Certifications has recently mandated that all undergraduate-level athletic training programs must develop into entry-level masters programs. With this change in degree status, a repeat study with degree-level considerations may be necessary. 


\section{ADDITIONAL REFERENCES}

31. Eckles RE, Meslin EM, Gaffney M, Helft PR. Medical ethics education: where are we? where should we be going? a review. Acad Med. 2005; 80(12):1143-52

32. Airth-Kindree N, Kirkhorn L. Ethical grand rounds: teaching ethics at the point of care. Nursing Edu Perspect. 2016;37(1):48-50.

33. National Athletic Trainers' Association Executive Committee for Education. Athletic training education competencies. https://www.nata.org/sites/default/files/competencies_5th_edition.pdf. Published 2011. Accessed November 15, 2016. 